\title{
A modeling approach to evaluate the uncertainty in estimating the evaporation behaviour and volatility of organic aerosols
}

\author{
E. Fuentes and G. McFiggans \\ Center for Atmospheric Science, School of Earth, Atmospheric and Environmental Sciences, Manchester, M13 9PL, UK \\ Correspondence to: G. McFiggans (g.mcfiggans@manchester.ac.uk)
}

Received: 4 October 2011 - Published in Atmos. Meas. Tech. Discuss.: 4 November 2011

Revised: 2 April 2012 - Accepted: 2 April 2012 - Published: 18 April 2012

\begin{abstract}
The uncertainty in determining the volatility behaviour of organic particles from thermograms using calibration curves and a kinetic model has been evaluated. In the analysis, factors such as re-condensation, departure from equilibrium and analysis methodology were considered as potential sources of uncertainty in deriving volatility distribution from thermograms obtained with currently used thermodenuder designs.
\end{abstract}

The previously found empirical relationship between $C^{*}$ (saturation concentration) and $T_{50}$ (temperature at which $50 \%$ of aerosol mass evaporates) was theoretically interpreted and tested to infer volatility distributions from experimental thermograms. The presented theoretical analysis shows that this empirical equation is in fact an equilibrium formulation, whose applicability is lessened as measurements deviate from equilibrium. While using a calibration curve between $C^{*}$ and $T_{50}$ to estimate volatility properties was found to hold at equilibrium, significant underestimation was obtained under kinetically-controlled evaporation conditions. Because thermograms obtained at ambient aerosol loading levels are most likely to show departure from equilibrium, the application of a kinetic evaporation model is more suitable for inferring volatility properties of atmospheric samples than the calibration curve approach; however, the kinetic model analysis implies significant uncertainty, due to its sensitivity to the assumption of "effective" net kinetic evaporation and condensation coefficients. The influence of re-condensation on thermograms from the thermodenuder designs under study was found to be highly dependent on the particular experimental condition, with a significant potential to affect volatility estimations for aerosol mass loadings $>50 \mu \mathrm{g} \mathrm{m}^{-3}$ and with increasing effective kinetic coefficient for condensation and decreasing particle size. These results show that the geometry of current thermodenuder systems should be modified to prevent re-condensation.

\section{Introduction}

Organic aerosols comprise a significant portion of atmospheric particular matter (Hallquist et al., 2009; Jimenez et al., 2009), with a long recognised impact on both human health and global climate (Kanakidou et al., 2005; Tsigaridis and Kanakidou, 2007). They comprise primary organic aerosol (POA) emissions from sources such as fossil fuel combustion, biomass burning and diverse industrial processes, and a secondary organic aerosol (SOA) contribution formed in the atmosphere from the gas phase oxidation of volatile organic compounds (Hallquist et al., 2009). The volatility of organic aerosols largely determine the partitioning of compounds between the gas and particle phases, hence influencing the particles mass concentration, composition and size, which in turn can affect the hygroscopicity and optical properties of organic aerosols in the atmosphere (Topping et al., 2011). Accurate representation of gas-particle partitioning of semi-volatile organic compounds, and its dependence on temperature, dilution conditions and chemical transformations in the atmosphere, is required for improving prediction of the global distribution of organic aerosols.

Particle evaporation studies in dilution chambers and thermodenuder systems are increasingly being conducted to characterise the volatility distribution and evaporation behaviour of primary and secondary organic aerosols in laboratory and field measurements (Huffman et al., 2008; Saleh et al., 2008; Faulhaber et al., 2009; Grieshop et al., 2009; 
Cappa and Wilson, 2011). A growing number of methods are being proposed in order to infer information on the volatility and thermodynamic properties of organic aerosol compounds from the evaporation profiles derived from this type of experiments (Faulhaber et al., 2009; Grieshop et al., 2009; Cappa and Wilson, 2011; Saleh et al., 2011). Some of these methods rely on the assumption that equilibrium is attained in the heating section of thermodenuder systems (Offenberg et al., 2006; Saleh et al., 2008). However, the observed dependence of thermograms on a thermodenuder's residence time indicates that equilibrium may not be attained under certain experimental conditions (An et al., 2007; Grieshop et al., 2009). Theoretical analysis of particle evaporation kinetics have shown that evaporation equilibration times in thermodenuders are highly dependent on factors such as aerosol mass loading and evaporation coefficient (Riipinen et al., 2010), resulting in evaporative equilibrium being attained only under laboratory conditions at organic aerosol loadings $>200 \mu \mathrm{g} \mathrm{m}^{-3}$ in systems with residence time $\geq 30 \mathrm{~s}$ (Riipinen et al., 2010; Saleh et al., 2011). The equilibration time can been shown to be independent of aerosol volatility so long as it is assumed that the change in particle size upon evaporation is small. However, because a change in the particle size is inherent to the evaporation process itself, deviation from the above assumption is expected as the volatility increases, implying longer equilibration time for increasing compounds volatility (Saleh et al., 2011). Since concentrations of organic aerosol at ambient levels are typically below $50 \mu \mathrm{g} \mathrm{m}^{-3}$ (Huffman et al., 2008), equilibrium is expected not to be reached in thermodenuder measurements with atmospheric samples due to the limited residence time usually applied in these systems (below $30 \mathrm{~s}$ ). Atmospheric measurements should therefore be interpreted using a kinetic rather than an equilibrium approach, otherwise this may result in significant deviations in determining the evaporation properties of the organic aerosol (Riipinen et al., 2010; Cappa and Jimenez, 2010). The use of evaporation kinetic models imposes a strong limitation in the input requirements of the properties of constituents of the particles, since in most cases even the identity of compounds in the aerosol sample is unknown (Cappa and Jimenez, 2010). In order to avoid the limitations imposed by detailed kinetic evaporation models, Faulhaber et al. (2009) proposed a method for deriving volatility distributions from thermograms, based on an empirical relationship found between the thermodenuder temperature at which $50 \%$ of the total mass of aerosol evaporates $\left(T_{50}\right)$ and the organic compound vapour pressure. Because this empirical calibration curve was derived from measurements at high organic aerosol loading (100-200 $\mu \mathrm{g} \mathrm{m}^{-3}$ ) with a limited set of organic compounds, while this method seems to provide good estimations for a variety of samples, it is still uncertain that it is valid for compounds and conditions other than those used for the calibration.

In addition to being used to infer volatility distribution of organic aerosols, evaporation profiles obtained from isother- mal dilution and thermodenuder experiments have been recently employed to derive effective kinetic coefficients, by coupling measurements and kinetic modelling for compounds of known volatility (Grieshop et al., 2009; Cappa and Wilson, 2011; Saleh et al., 2012). This approach has proven useful in determining evaporation coefficients for single compounds such as dicarboxylic acids (Cappa, 2010; Saleh et al., 2011), POA mixtures such as lubricating oil (Grieshop et al., 2009; Cappa and Wilson, 2011) and amorphous solid SOA derived from $\alpha$-pinene ozonolysis (Cappa and Wilson, 2011). Inconsistencies exist, however, between the evaporation coefficients estimated from isothermal dilution and thermodenuder measurements for compound mixtures like lubricating oil (Grieshop et al., 2009; Cappa and Wilson, 2011). Whether this discrepancy is a result of different volatility composition resulting from the use of different aerosol generation techniques, or to artefacts derived from the evaporation methodologies applied, is unresolved.

Re-condensation has long been considered as a potential concern for the interpretation of evaporation profiles from thermodenuder measurements, as this would lead to an underestimation of a particle's volatility (Burtscher et al., 2001; Wehner et al., 2002; Huffman et al., 2008). To minimise this effect, charcoal denuders are included in the cooling section of many standard designs, such that the semi-volatile material is removed from the gas-phase, and re-condensation is suppressed as the aerosol sample cools down (Burtscher et al., 2001; Wehner et al., 2002). Experiments by Huffman et al. (2008) have proven that sulphuric acid particles present a potential for re-condensation in thermodenuder cooling sections at aerosol loadings $\leq 50 \mu \mathrm{g} \mathrm{m}^{-3}$, while recondensation for organic compounds of higher volatility than sulphuric acid, has been found to be negligible. Volatility studies on Diesel exhaust and marine aerosols with volatility tandem differential mobility analyser (VTDMA) instruments have shown insignificant re-condensation in cooling sections (Orsini et al., 1999; Sakurai et al., 2003); however, it is considered that the rate of re-condensation in these systems is lower than in thermodenuder instruments owing to the low particle surface area available after size selection (Huffman et al., 2008). Modelling calculations by Cappa (2010) for high volatility compounds $\left(C^{*}=10 \mu \mathrm{g} \mathrm{m}^{-3}\right)$ have shown that the potential for re-condensation is likely to be substantial at laboratory conditions with organic aerosol loadings $>200 \mu \mathrm{g} \mathrm{m}^{-3}$, while being of low significance for ambient aerosol loading levels. Recent modelling and experimental work by Saleh et al. (2011) indicate that re-condensation would be negligible even for high organic aerosol mass loadings, if the geometry of the cooling section is adequately modified. Significant re-condensation in Cappa (2010) was a result of the geometry of the thermodenuder design applied, which yields a dimensionless number $\mathrm{Cn}$ greater than the maximum value established for negligible re-condensation by Saleh et al. (2011) . Differences between conclusions by Cappa (2010) and Saleh et al. (2011) regarding the potential 
of re-condensation and performance of charcoal denuders also originate from their definition of the absorbing potential of the walls of the cooling section. While Cappa (2010) provided lower and upper estimates for re-condensation derived from the assumptions of local equilibrium and non absorbing conditions at the walls, Saleh et al. (2011) based their calculations on an assumption of equilibrium wall condensation, thus providing a lower estimate for re-condensation.

In this work a kinetic evaporation-condensation model in an axisymmetrical thermodenuder geometry is applied to assess the interpretation of particle mass evaporation profiles obtained at conditions relevant to both ambient and laboratory measurements. The main aims of this study are (1) to evaluate the uncertainty in estimating volatility distributions from measurements derived from current thermodenuder designs, including deviations resulting from re-condensation and/or assumptions of equilibrium and kinetic mass transfer coefficients; (2) to provide theoretical interpretation for the empirical calibration between the temperature at which $50 \%$ of organic aerosol mass evaporates $\left(T_{50}\right)$ and vapour pressure, and assess its validity for deriving volatility distributions from thermograms at a variety of conditions and (3) to provide insights on the interpretation of particle evaporation behaviour and effective kinetic evaporation coefficients for a set of primary and secondary organic aerosol samples.

\section{Thermodenuder model}

A diffusion-evaporation model was applied to simulate the evaporation/re-condensation of particles in a cylindrical geometry thermodenuder system. The thermodenuder configuration consists of a typical design, as illustrated in Fig. 1. The model was sequentially solved on the three sections of the thermodenuder: the heating section, where the particles are subject to evaporation; the cooling section, which is the short intermediate piece of tubing where the sample approaches ambient temperature; and the denuder section, which comprises the piece of tubing where gas-phase semivolatile compounds are removed by a charcoal adsorber in order to avoid re-condensation. Figure 1 summarises the dimensions and residence time in each part of the design.

The thermodenuder model simulates the gain and loss of material in the condensed phase resulting from evaporation and re-condensation, respectively, the transport of the gas and the evolution of the particle diameter. The steady-state evaporation/re-condensation and diffusion of a gaseous compound through a cylindrical tube, assuming azimuthal symmetry and constant coefficient of diffusion, is defined as (Tan and Hsu, 1970):

$v_{x} \frac{\partial C_{i}}{\partial x}+v_{r} \frac{\partial C_{i}}{\partial r}=D_{i}\left[\frac{1}{r} \frac{\partial}{\partial r}\left(r \frac{\partial C_{i}}{\partial r}\right)+\left(r \frac{\partial^{2} C_{i}}{\partial x^{2}}\right)\right]+q_{i}$

where $v_{x}$ and $v_{r}$ are the fluid velocity in the axial and radial directions, respectively, $C_{i}$ is the gas phase mass con-

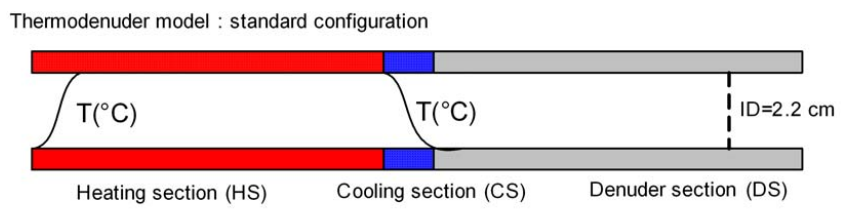

Thermodenuder model : denuder bypass configuration

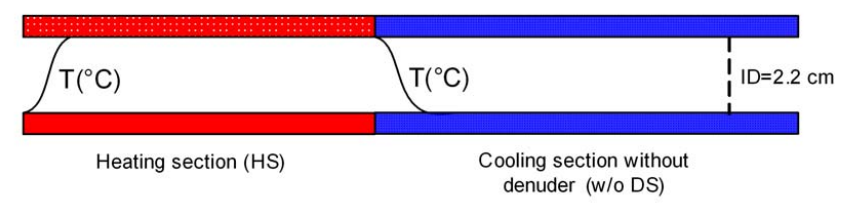

$$
\begin{array}{cl}
\text { HS } & \left.50 \mathrm{~cm} \text { (19 s Plug flow RT, } 25^{\circ} \mathrm{C}\right) \\
\text { CS } & 15 \mathrm{~cm}\left(5.7 \mathrm{~s} \text { Plug flow RT, } 25^{\circ} \mathrm{C}\right) \\
\text { DS } & 50 \mathrm{~cm}\left(19 \mathrm{~s} \text { Plug flow RT, } 25^{\circ} \mathrm{C}\right) \\
\text { w/o DS } & 65 \mathrm{~cm}\left(24.7 \mathrm{~s} \text { Plug flow RT, } 25^{\circ} \mathrm{C}\right)
\end{array}
$$

Fig. 1. Schematic of the thermodenuder design used for the calculations. The configuration with denuder bypass was also calculated to explore the potential for re-condensation and the efficiency of the charcoal denuder. Air flow $=0.6 \mathrm{lpm}, \mathrm{RT}=$ residence time.

centration of compound $i, D_{i}$ is the gas diffusion coefficient, $q_{i}$ is the source/sink term for the gas phase due to particle evaporation/re-condensation, and $x$ and $r$ are the axial and radial coordinates, respectively. Equation 1 was simplified under the assumption of negligible secondary flows and diffusion in the axial direction, such that the terms involving $v_{r}$ and $\frac{\partial^{2} C_{i}}{\partial x^{2}}$ are eliminated from the equation. The assumption for negligible axial diffusion is valid for Péclét number of diffusion $>100$ (Turpin et al., 1993), which applies to the geometry and conditions in this study $(\mathrm{Pe}=115)$. The convective term for secondary flows $v_{r}$ was considered to be negligible compared to the axial velocity term in Eq. (1). This assumption will be further validated by comparing with experimental results.

The term $q_{i}$, which denotes the mass gain/loss in the gas or particle phase $\left(C_{\mathrm{p}, i}\right)$ due to evaporation or re-condensation, is defined as (Seinfeld and Pandis, 1997; Cappa, 2010):

$q_{i}=v_{x} \frac{\partial C_{i}}{\partial x}=-v_{x} \frac{\partial C_{\mathrm{p}, i}}{\partial x}=2 \pi N D_{i} d_{\mathrm{p}} \Gamma\left(x_{i} C_{i}^{*}-C_{i}\right)$

where $N$ is the particle number, $d_{\mathrm{p}}$ is the particle size, $\Gamma$ is the Fuchs and Sutugin (1970) correction term, defined as a function of the accommodation coefficient $\alpha, x_{i}$ is the compound mass fraction in the particle and $C_{i}^{*}$ is the compound saturation concentration.

It has been shown by Laaksonen et al. (2005) that the accommodation coefficient should exhibit a value of unity for models to adequately represent the physics of evaporation and condensation at the molecular limit. It should be noted, that the kinetic coefficients used in the present study are defined to account for all the potential kinetic limitations. As an example, the kinetics of evaporation of nonliquid particles may be expected to be greatly influenced by 
the diffusion coefficient through a viscous solution (e.g. Tong et al., 2011). Although such behaviour should be tested in appropriate model frameworks (Pfrang et al., 2011), kinetic limitations will be evaluated in the present work in terms of an "effective" uptake coefficient $\gamma^{\prime}$, which comprises all kinetic limitations to mass transfer from the aerosol to the gas phase and viceversa. Where the kinetic limitation to evaporation and recondensation are considered of different magnitude, the uptake coefficient is split into an effective net evaporation coefficient $\left(\gamma_{\text {evap }}^{\prime}\right)$ and a net uptake re-condensation coefficient $\left(\gamma_{\text {cond }}^{\prime}\right)$ for the evaporation and re-condensation processes, respectively. The physical behaviour we are aiming to represent in using different coefficients in condensation or evaporation is the limitation to the kinetic rate in one direction or another. In other words, the effective kinetic coefficients are valid as empirical parameters that are indicative of the kinetic limitations in the system, but they are not applicable to interpret the system behaviour at the molecular limit, as this may lead to unphysical behaviour. However, as shown in previous studies (Cappa and Wilson, 2011) the use of "effective" kinetic coefficients is still an useful approach for analysing and modeling the kinetic limitations involved in the process.

The boundary conditions applied to solve Eqs. (1) and (2) in the heating section are:

$$
\begin{aligned}
& C_{i}(0, r)=C_{i 0,298} \\
& \frac{\partial C_{i}(x, R)}{\partial x}=0
\end{aligned}
$$

where $R$ is the thermodenuder radius. The first boundary equation is a constraint for the initial concentration of the organic compounds in the gas phase. The concentration of gas at the inlet of the heating section $\left(C_{i 0,298 \mathrm{~K}}\right)$ is defined considering that the aerosol is in equilibrium at ambient temperature, and that the distribution of the organic compounds between the gas and particle phases is defined by the adsorptive partitioning theory (Pankow, 1994). The second boundary equation is a Neumann boundary condition under the assumption of no mass losses to the walls of the system.

For the cooling section, the initial gas phase concentration is given by the heating section output gas distribution. Although wall condensation is likely to occur in the cooling section (Saleh et al., 2011), local equilibrium at the walls may not be achieved at all conditions. To infer the potential for re-condensation the model was applied to provide for lower and upper estimates of recondensation by considering both the limiting wall boundary conditions defined by no mass transfer to the walls (upper limit for re-condensation) and equilibrium wall condensation (lower limit for re-condensation) (Cappa, 2010). The boundary condition of no mass transfer to the walls is equal to the condition for the heating section, while the equilibrium wall condensation is given by $C_{i}(x, R)=x_{i}(x, R) C_{i}^{*}$, i.e. the equilibrium concentration of each compound at the wall temperature.
The boundary conditions considered to solve the diffusionevaporation equation in the denuder section are:

$$
\begin{aligned}
& C_{i}(0, r)=C_{i 0, \mathrm{DS}} \\
& C_{i}(x, R)=0
\end{aligned}
$$

The first equation defines the initial conditions for the denuder section, which are given by the output gas concentration from the cooling section, while the second equation is a Dirichlet condition defining the denuder walls as a perfect sink for the gas phase. The assumption of perfect sink implies that the gas is bound completely and irreversibly upon coming into contact with the coating material. The modeled denuder performance therefore represents an upper limit on the efficiency of the system to remove semi-volatile gas.

The temperature distribution of the gas in the heating and cooling sections was modelled using the heat equation, under the assumptions of fully developed laminar flow and negligible secondary flows and heat transfer in the axial direction as (Campo, 2004):

$$
\rho c_{\mathrm{p}} v_{x} \frac{\partial T}{\partial x}=k\left[\frac{1}{r} \frac{\partial}{\partial r}\left(r \frac{\partial T}{\partial r}\right)\right]
$$

The assumption of fully developed flow at the entrance of the thermodenuder was adopted, given that the entrance length for a laminar flow to become fully developed in the system under study is as short as $3 \mathrm{~cm}$. The assumptions of negligible radial flow with respect to the axial velocity term and negligible heat transfer diffusion in the axial direction are validated in the next section by comparing the modelled temperature distribution with experimental temperature profiles from Huffman et al. (2008).

The heat equation in the heating and cooling sections was solved for the following boundary conditions:

$$
\begin{aligned}
& T(0, r)=T_{0,298 \mathrm{~K}(\mathrm{CS})} \\
& T(x, R)=T_{\text {wall }} \\
& \frac{\partial T}{\partial r}=0
\end{aligned}
$$

where the first equation specifies ambient temperature conditions $T_{0,298 \mathrm{~K}}$ for the flow at the entrance of the heating section and a cooling section initial temperature $\left(T_{0, \mathrm{CS}}\right)$ defined by the output of the heating section. The second condition specifies the wall temperature at all axial positions and the third equation is the symmetry condition. In the heating section the wall temperature is set equal to the set point temperature, while in the cooling section the wall boundary condition was the ambient temperature, with heat transfer occurring only between the wall and the sample air flow.

The velocity of the fluid was modelled as a function of the local temperature, using the definition of plug flow velocity. A plug flow velocity profile was found to be a better approximation than the parabolic profile for estimating the particle evaporation/re-condensation rate for the constant particle 
concentration radial profile employed in our model. A real particle concentration radial profile would have a parabolic shape, with near-zero particle concentration in the vicinity of the walls (due to diffusion and thermophoretic losses) and a maximum particle concentration at the centerline (Shimada et al., 1993). Hence, the gas production near the walls of the heating section would be low in a real system, because there would be few particles at this region. The constant particle concentration profile that we use, however, implies having a high particle concentration near the walls, which together with the long residence time defined by the parabolic velocity profile at the walls, leads to an overestimation of gas production in this zone. This happens not just at the bin adjacent to the wall, but in the region within $\sim 20 \%$ radial distance from the wall where velocities are low. The overestimated production of gas near the walls in the heating section leads to diffusion of gas towards the centerline, thus reducing the evaporation rate of particles at other radial positions. Similar artifact occurs in the cooling section, due to an overestimation of the particle re-condensation rate in the vicinity of the walls. Our comparison with experimental results show that, in the absence of a model for the particle concentration radial distribution, the combination of a plug flow velocity and plug flow particle concentration profiles provides a better approximation for the averaged particle evaporation/re-condensation rates than using the velocity parabolic profile with a constant particle concentration radial profile. It is recognised that these assumptions do not ideally represent the wall interactions, but it is demonstrated below that the mean behaviour is well represented. Better representation of the radial profile including wall losses would require simulation of the particle number profiles by calculation of particle trajectories and numerical solution of Navier Stokes equations. This is beyond the scope of the current study.

For the aerosol evaporation calculations a one-way coupling approach between the particles and the continuous phase was adopted, on the assumption that the size and loading of particles is low enough as to negligibly affect the fluid properties. The fluid temperature, density and velocity distribution in the system were first calculated for the given wall temperature and flow boundary conditions, followed by the injection of particles in the model to conduct the particle evaporation/re-condensation evolution calculations. The evaporation-diffusion equations given by Eqs. (1) to (6) were solved by applying sequential numerical integration on the nodes of a cylindrical geometry axysimmetric grid with a resolution of $0.2 \mathrm{~mm}$ in the radial direction and $5 \mathrm{~mm}$ in the longitudinal direction. Increase in the resolution of the system did not result in a significant change in the results of the model. The system of Eqs. (1)-(2), together with the stated boundary conditions and input of the spatial fluid properties, constitutes a system of coupled non-linear partial and ordinary differential equations, which was iteratively solved using the method of lines integration solution with Galerkin/Petrov-Galerkin spatial discretisation

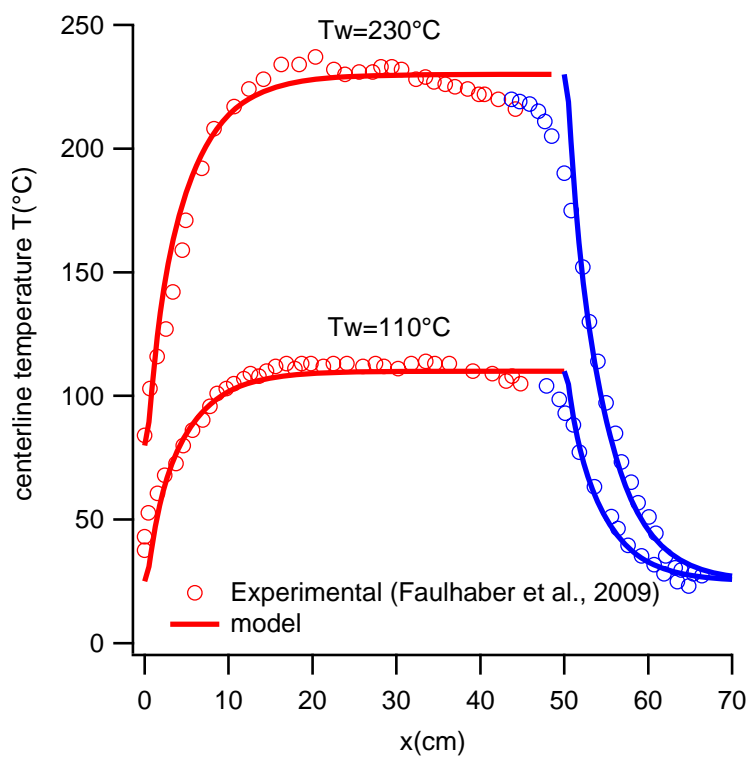

Fig. 2. Modeled and experimental centerline temperature in the heating and cooling sections of Huffman et al. (2008) thermodenuder. Note that the initial fluid temperature in this calculation is the centerline temperature at the inlet of the active heating zone (i.e. tube covered with heating tapes).

(Skeel and Berzins, 1990), and an explicit Runge-Kutta formula method, both implemented in solvers in the commercial software Matlab. It should be noted that this model has initially been designed to simulate the behaviour of monodisperse aerosol samples. An extension of the model would be required so that it can be used to represent polydisperse distributions. This can be done by implementing models such as the condensation sink diameter approach (Lehtinen et al., 2003; Saleh et al., 2011).

\section{Fluid properties}

Figure 2 illustrates the modelled axial evolution of the fluid temperature in the heating and cooling sections of a thermodenuder with dimensions and operating conditions identical to those described in Huffman et al. (2008), in comparison with experimental centerline temperature measurements provided in the cited work. The initial temperature of the fluid in the model was set equal to the fluid temperature at the inlet of the active heating zone in Huffman et al. (2008) (i.e. zone covered with heating tapes), so that the thermodenuder wall temperature could be applied as a boundary condition. The wall temperature was set to the value of maximum temperature reached by the fluid in the experimental system. As shown in Fig. 2, the modelled and experimental temperature profiles are in good agreement, thus indicating that the assumptions previously made are valid for modelling the temperature and fluid properties. Calculations at different wall temperatures indicate that, for the dimensions and operating 
conditions applied, the wall temperature boundary condition is reached in the centerline at $\sim 15-20 \mathrm{~cm}$ from the beginning of the heating section. As an example of temperature distributions, Fig. S1 shows the temperature field in the heating section of the thermodenuder for a wall temperature of $100^{\circ} \mathrm{C}$. The temperature distribution affects both the density and, consequently, the velocity of the fluid, leading to an acceleration and deceleration of the fluid in the heating and cooling section, respectively.

\section{Re-condensation: parametric analysis}

A parametric sensitivity study was conducted in order to evaluate the potential of re-condensation to affect thermodenuder evaporation profiles and the subsequent interpretation of volatility. For the analysis, the influence of aerosol loading $\left(C_{\mathrm{OA}}\right)$, particle size $\left(d_{\mathrm{p}}\right)$, kinetic coefficient $\left(\gamma^{\prime}\right)$, volatility $\left(C^{*}\right)$ and diffusion coefficient $\left(D_{i}\right)$ on gas re-condensation, was evaluated by comparing thermograms obtained after the heating, cooling and denuder sections in the thermodenuder model. The output thermogram for an equivalent system without denuder section was also calculated in order to asses the level of re-condensation and the performance of the charcoal denuder. The mass fraction remaining, calculated as a function of the heater temperature, was defined as MFR $=M_{\mathrm{f}} / M_{0}$, where $M_{\mathrm{f}}$ is the aerosol mass after the corresponding section in the thermodenuder and $M_{0}$ is the initial aerosol mass in the system $\left(M_{0}\right.$ is equivalent to the mass referenced to the bypass without thermodenuder, corrected for particle losses). Because the density of the particles was assumed to be constant, the mass fraction remaining is equivalent to a volume fraction remaining. Together with the thermograms comparison, the results were also evaluated in terms of re-condensation fraction (RF), defined as the percent of evaporated gas that re-condenses onto the particles after the cooling section $\left(C_{\mathrm{CS}}\right)$ or the denuder section $\left(C_{\mathrm{DS}}\right)$ with respect to the amount of gas exiting the heating section $\left(C_{\mathrm{HS}}\right)$ :

$\mathrm{RF}(\%)=\frac{C_{\mathrm{HS}}-C_{\mathrm{CS}(\mathrm{DS})}}{C_{\mathrm{HS}}} \cdot 100$

Positive values of RF indicate that the gas evaporated in the heating section recondenses in the cooling or denuder sections, while negative values indicate an increase in the gas concentration with respect to the amount of gas at the exit of the heating section. Negative values of the re-condensation fraction are expected if the removal of gas by denudation induces the evaporation of particles in the denuder section. It should be noted that the values of re-condensation fraction presented here are different to those determined in Saleh et al. (2011). While we provide RF values at the end of the cooling or denuder section for a given tube length, re-condensation fraction estimations in Saleh et al. (2011) represent the maximum re-condensation (i.e. if equilibrium is attained in the cooling section). It should be noted that the definition of recondensation fraction presented here is different to the maximum re-condensation fraction values determined in Saleh et al. (2011).

For the parametric analysis, the case with $d_{\mathrm{p}}=100 \mathrm{~nm}$, $\gamma^{\prime}=1, \quad C^{*}=0.1 \mu \mathrm{g} \mathrm{m}^{-3} \quad$ and $\quad C^{*}=0.01 \mu \mathrm{g} \mathrm{m}^{-3}$, $C_{\mathrm{OA}}=400 \mu \mathrm{g} \mathrm{m}^{-3}$ and $D_{i}=5 \times 10^{-6} \mathrm{~m}^{2} \mathrm{~s}^{-1}$ was selected for the baseline conditions. The heat of vaporisation generally correlates with the saturation concentration, exhibiting an increasing value for decreasing volatility (Epstein et al., 2009). In order to apply an enthalpy of vaporisation consistent with the compound's volatility, the equation derived by Epstein et al. (2009) was applied. For the volatilities above indicated, this expression yields near-room temperature enthalpy values of $151 \mathrm{~kJ} \mathrm{~mol}^{-1}$ and $140 \mathrm{~kJ} \mathrm{~mol}^{-1}$, respectively. In the model, a constant heat of vaporisation was assumed over the temperature range considered. The thermodenuder geometry applied was similar to that described in Huffman et al. (2008), with dimensions, residence times and flow as indicated in Fig. 1.

Figure 3 shows the thermograms obtained after the different thermodenuder sections for $C^{*}=0.01 \mu \mathrm{g} \mathrm{m}^{-3}$ at diverse organic aerosol loading levels. The equilibrium evaporation thermograms have also been included for comparison. In the re-condensation process, equilibrium is achieved when the initial aerosol mass is reached, i.e. for $M F R=1$. Upper and lower estimates for re-condensation included in the figures, show that the assumption for the wall conditions substantially affects the significance of re-condensation. In agreement with results in Cappa (2010), the re-condensation potential is highly dependent on the aerosol loading and particularly promoted at high aerosol loading levels, which are typically used in laboratory experiments (Faulhaber et al., 2009; Cappa and Wilson, 2011). Predictions for the upper estimate indicate that an already significant re-condensation could occur in the $15 \mathrm{~cm}$ cooling section joining the heater and the denuder sections for organic loadings $\geq 150 \mu \mathrm{g} \mathrm{m}^{-3}$. In addition, the removal of gas by the denuder at high organic loadings is not sufficient to avoid further re-condensation, which in the case of $400 \mu \mathrm{g} \mathrm{m}^{-3}$ loading leads to the recondensation fraction being reduced in only a $\sim 10 \%$ with respect to the same length of tubing without denuder. The efficiency of the denuder in preventing re-condensation is considerably higher for lower organic loading, with reductions $\geq$ $45 \%$ in the re-condensation fraction, with respect to the case without denuder for aerosol loadings $\leq 150 \mu \mathrm{g} \mathrm{m}^{-3}$. The upper estimate for re-condensation for $30 \mu \mathrm{g} \mathrm{m}^{-3}$, (Fig. S4a) also indicate that no significant modification of the thermograms is expected at atmospheric conditions below this concentration. Although atmospheric aerosol loadings can reach values as low as $1-5 \mu \mathrm{g} \mathrm{m}^{3}$, simulations at these aerosol concentrations have not been performed as these conditions are not relevant for the re-condensation analysis. The results for lower estimates for re-condensation show that, although the re-condensation degree is considerably lower than for the 


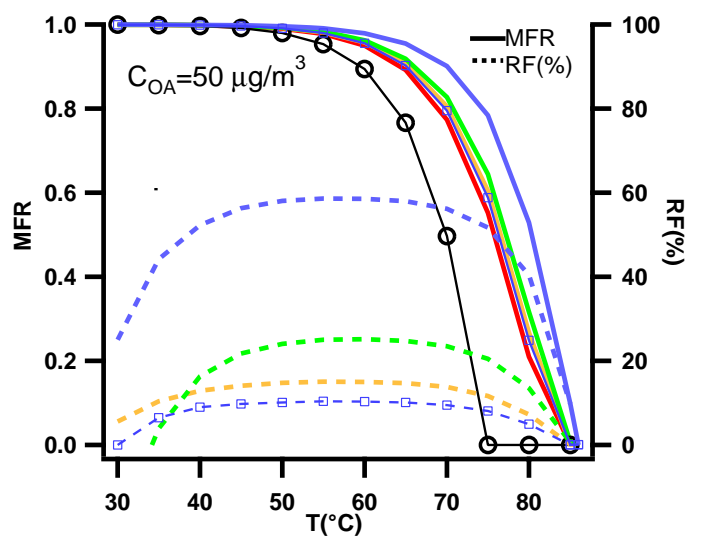

upper estimate, there is still a potential for re-condensation for aerosol loadings above $50 \mu \mathrm{g} \mathrm{m}^{-3}$. Detailed calculations on the effect of the aerosol mass loading under the assumption of equilibrium wall condensation are presented as supplementary material (Figs. S2 and S3). The performance of the charcoal denuder is similar to that of the cooling section under the assumption of wall equilibrium condensation for volatilities below $10 \mu \mathrm{g} \mathrm{m}^{-3}$. This is because the gas bulk concentration is much higher than $C^{*}$ and the gradient between the bulk and the walls of the cooling section is similar in the charcoal denuder and equilibrium wall conditions cases (i.e. $\mathrm{Cg}-C^{*} \sim \mathrm{Cg}-0$ ).

Corresponding results for visualising the relationship be-

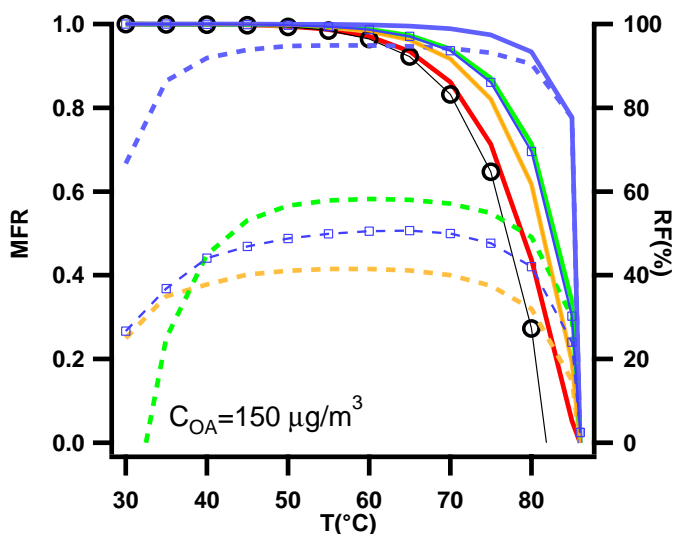
tween volatility and re-condensation are presented in Fig. 4. For a given MFR value, the curves for the cooling section (CS and w/o DS) for $C^{*} \leq 1 \mu \mathrm{g} \mathrm{m}^{-3}$ indicate that the recondensation fraction does not seem to be substantially affected by the volatility of the organic aerosol. This is a result of the lower temperatures required to achieve the same level of evaporation for high volatility compounds with respect to the low volatility cases, which leads to gradients for re-condensation of similar magnitude for compounds of different volatility. Lower re-condensation is however, observed in the $C^{*}=10 \mu \mathrm{g} \mathrm{m}^{-3}$ thermogram after the cooling and denuder sections with respect to the lower volatility cases. Furthermore, the results show that particle evaporation may be induced by the charcoal denuder, leading to modifications of thermograms for $C^{*}>1 \mu \mathrm{g} \mathrm{m}^{-3}$ and temperatures below $45^{\circ} \mathrm{C}$. Further analysis has shown that this effect is only important for $C^{*}>1 \mu \mathrm{g} \mathrm{m}^{-3}$, even at low aerosol loadings (Fig. S4b). Indeed, at $50 \mu \mathrm{g} \mathrm{m}^{-3}$ aerosol mass, evaporation induced by denudation has been predicted to be significant for volatilities $C^{*}>1 \mu \mathrm{g} \mathrm{m}^{-3}$ (Cappa, 2010). Because the significance of this effect is limited to a narrow range of temperatures and volatility compounds it is likely that the impact of denudation on thermograms is of low significance for ambient multicomponent mixtures. For laboratory experiments at high aerosol loadings, the mass of high volatility compounds is significant and the evaporation effect induced by the denuder may be more important than for ambient measurements.

As illustrated in Fig. 5, the kinetics of evaporation/recondensation are strongly affected by the effective kinetic coefficient value. Whilst it is recognised that this coefficient should not be used to represent all possible kinetic limitations to particle equilibration, its variation can be used to investigate potential instrument responses. Results in Fig. 5 show that reductions of the effective kinetic coefficient by an order of magnitude leads to a $\geq 50 \%$ suppression of the recondensation fraction, with negligible re-condensation predicted for $\gamma^{\prime} \leq 0.01$. It is also noticeable that decreasing kinetic coefficients push the system away from attaining equilibrium and that equilibrium is not reached for $\gamma^{\prime} \leq 0.1$, even for the high aerosol loading used in the calculations. In the work of Saleh et al. (2011), a thermodenuder with 

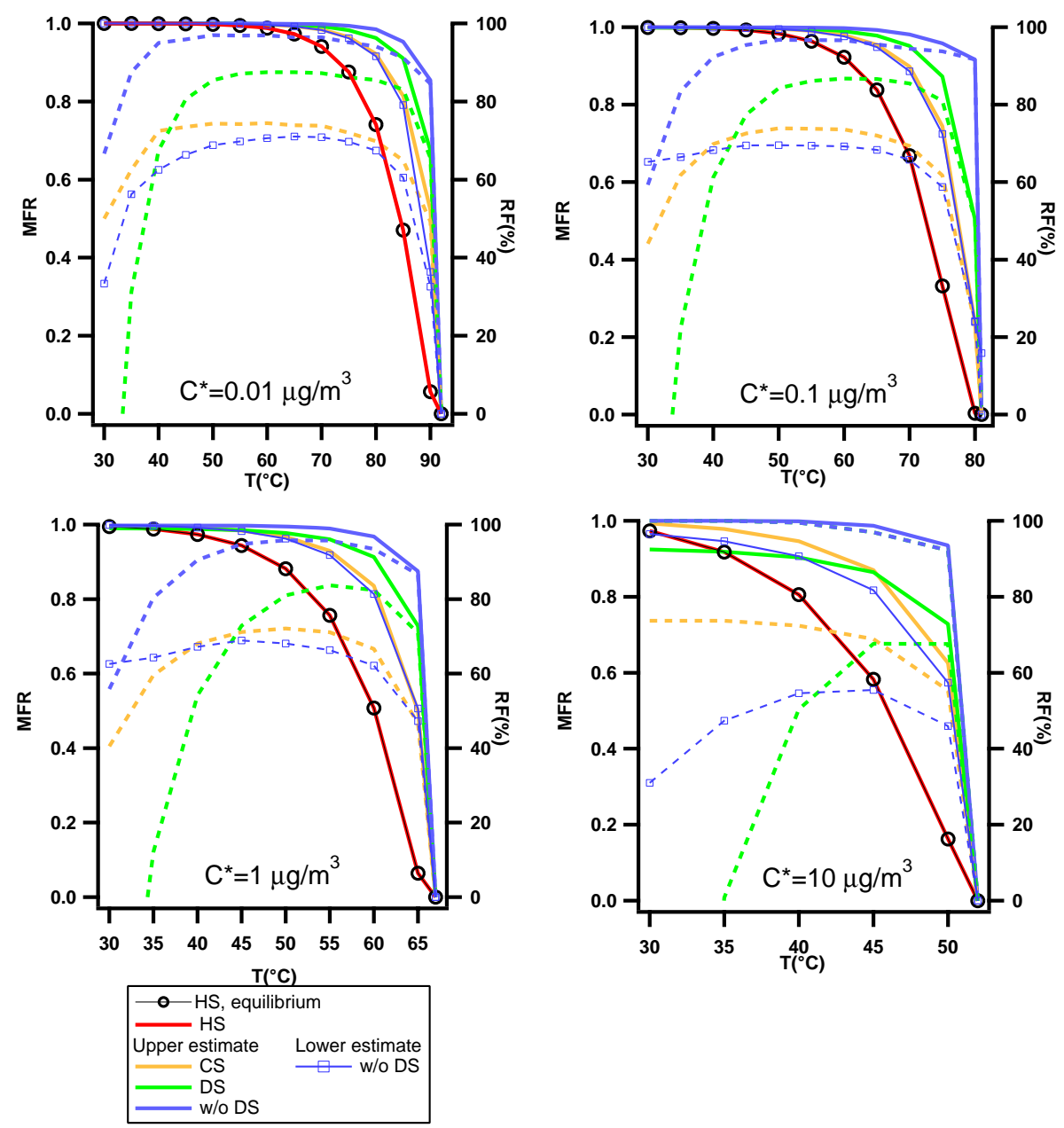

Fig. 4. Output thermograms and recondensation fraction for the heating section (HS), cooling section (CS), denuder section (DS) and equivalent configuration without denuder section (w/o DS) at different volatilities. Similar magnitude in the re-condensation fraction between the different volatility cases is obtained at equal MFR, due to the increase in volatility being counteracted by the low equilibrium saturation concentrations at low temperatures. The charcoal denuder is predicted to substantially influence thermograms only for $C^{*}>1 \mu \mathrm{g} \mathrm{m}^{-3}$ and temperatures below $45^{\circ} \mathrm{C}$, by inducing particle evaporation. Baseline case: $C_{\mathrm{OA}}=400 \mu \mathrm{g} \mathrm{m}^{-3}, d_{\mathrm{p}}=100 \mathrm{~nm}, D_{i}=5 \mathrm{e}-6 \mathrm{~cm}^{2} \mathrm{~s}^{-1}$ and $\gamma^{\prime}=1$.Upper estimate: upper estimate for re-condensation (no mass transfer to walls); lower estimate: lower estimate for re-condensation (equilibrium wall condensation).

longer heating section residence time than the system in the present study was employed (plug flow residence time of $\sim 30 \mathrm{~s}, 298 \mathrm{~K}$ ), allowing equilibrium to be attained for $\gamma^{\prime}=0.1$. However, it is foreseen that equilibrium will not be reached in a $30 \mathrm{~s}$ residence heating system for $\gamma^{\prime}<0.1$, regardless of the aerosol mass loading.

Another factor notably affecting the kinetics of recondensation is the particle size, as shown in Fig. 6. For constant aerosol loading, an increase in the particle size implies a reduction in the total particle surface area, which results in a deceleration of the re-condensation process. In contrast, the diffusion coefficient does not substantially affect the recondensation process, as reflected by the slight change in the thermograms between the expected range of values for this parameter (Fig. S5).
The strong dependence of the re-condensation rate on the particle size, kinetic coefficient and aerosol loading implies that the degree of re-condensation should be predicted considering the combined, rather than the isolated effects of these factors. Although the re-condensation rate will be enhanced by increasing aerosol loading, increasing kinetic coefficient and decreasing particle size, negligible recondensation could still be possible at certain high organic loadings, with sufficient large particle size or low kinetic coefficients. Analysis of the re-condensation occurring for a set of real cases, implying the combination of the above studied parameters, is presented in the next section.

The geometry of the thermodenuder system tested in this study, although representative of currently used thermodenuder designs, is problematic regarding re-condensation 

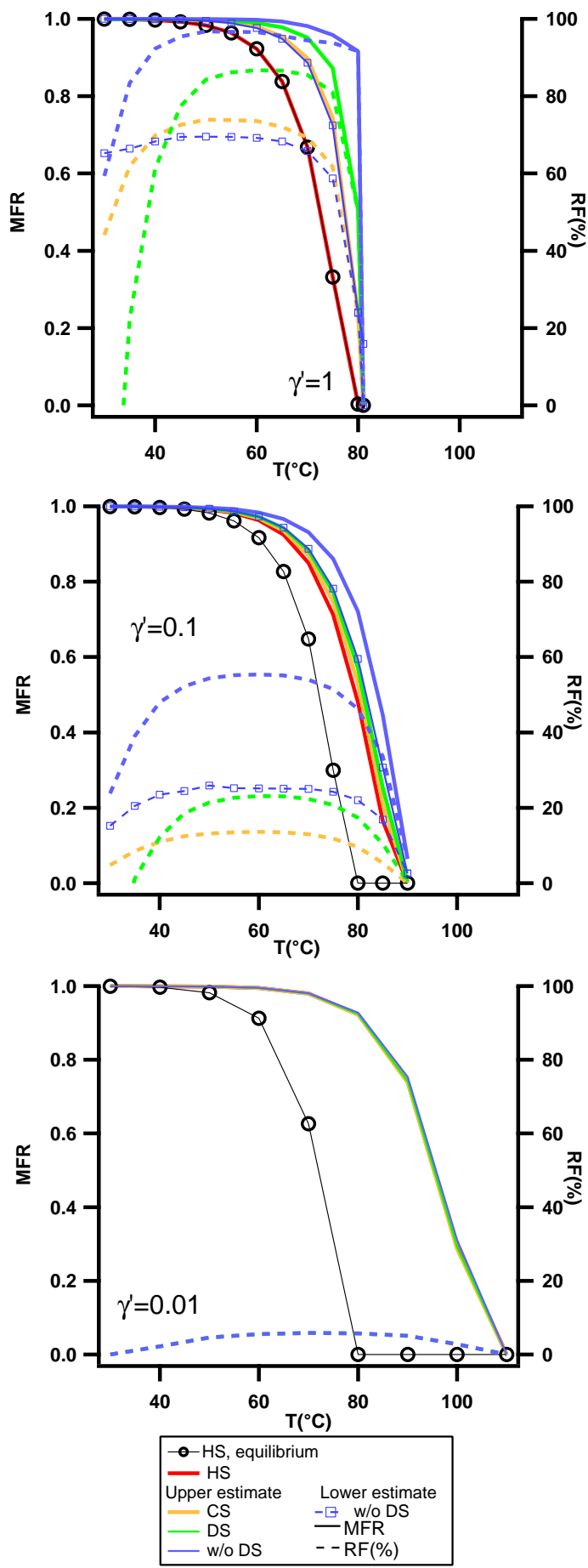

Fig. 5. Output thermograms and recondensation fraction for the heating section (HS), cooling section (CS), denuder section (DS) and equivalent configuration without denuder section (w/o DS) at different effective kinetic coefficients. Baseline case: $\mathrm{C}_{\mathrm{OA}}=$ $400 \mu \mathrm{g} \mathrm{m}^{-3}, C^{*}=0.1 \mu \mathrm{g} \mathrm{m}^{-3}, d_{\mathrm{p}}=100 \mathrm{~nm}$ and $D_{i}=5 \mathrm{e}-6 \mathrm{~cm}^{2} \mathrm{~s}^{-1}$. Upper estimate: upper estimate for re-condensation (no mass transfer to walls); lower estimate: lower estimate for re-condensation (equilibrium wall condensation).

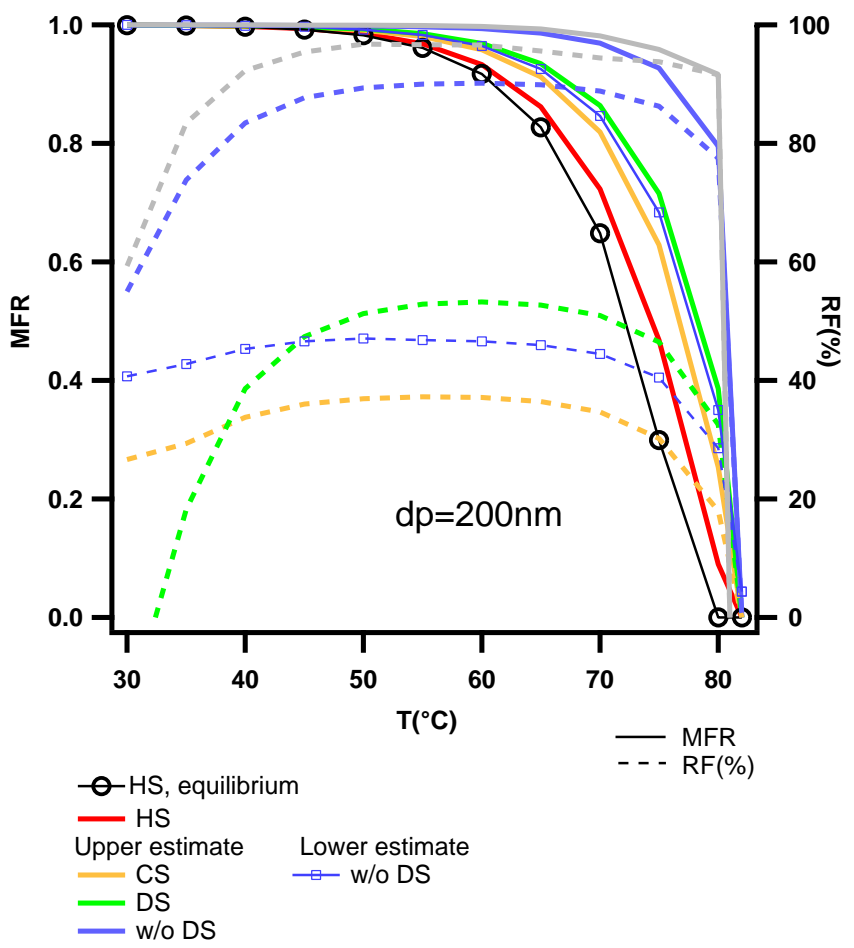

Reference curves for $\mathrm{dp}=100 \mathrm{~nm}$ (upper estimate) w/o DS

Fig. 6. Output thermograms and recondensation fraction for the heating section (HS), cooling section (CS), denuder section (DS) and equivalent configuration without denuder section (w/o DS), in a system with $200 \mathrm{~nm}$ aerosol particle size at $400 \mu \mathrm{g} \mathrm{m}^{-3}$ aerosol loading. Comparison of this plot with Fig. 5 at $\gamma^{\prime}=1\left(d_{p}=100 \mathrm{~nm}\right)$ indicates a deceleration in the re-condensation process for increasing particle size, at constant aerosol loading. This is a result of a reduction in the particle number available, which leads to slower evaporation and re-condensation rates. Baseline case: $C^{*}=0.1 \mu \mathrm{g} \mathrm{m}^{-3}$, $\gamma^{\prime}=1$ and $D_{i}=5 \mathrm{e}-6 \mathrm{~cm}^{2} \mathrm{~s}^{-1}$. Upper estimate: upper estimate for re-condensation (no mass transfer to walls); lower estimate: lower estimate for re-condensation (equilibrium wall condensation).

because of the large diameter of the cooling section. We have reproduced measurements by Saleh et al. (2011) and found negligible upper estimates of re-condensation for an initial $287 \mathrm{\mu g} \mathrm{m}^{-3}$ aerosol mass loading (Fig. S6). This negligible re-condensation is, in fact, a consequence of the small cooling section tube diameter used by Saleh et al. (2011), which leads to very short residence times $(0.93-1.87 \mathrm{~s}$, tube of $1-$ $2630 \mathrm{~m}$ length, flow $=1-21 \mathrm{pm}$ and ID of $0.63 \mathrm{~cm}$ ), compared to the typical residence time in cooling sections of diverse currently used thermodenuder models (e.g. $15.5 \mathrm{~s}$. in thermodenuder by Huffman et al. (2008), with CS+DS tube length $0.55 \mathrm{~m}$, flow $=0.61 \mathrm{pm}$ and $\mathrm{ID}=1.91 \mathrm{~cm}$ ). This, together with the low kinetic coefficient $\sim 0.1$ of the aerosol sample in Saleh et al. (2011) results in a limited growth of particles in the test by-pass tube with respect to the conditions at the tube inlet. It should be noted that the conclusion 
of negligible re-condensation at high aerosol loadings from experiments in Saleh et al. (2011) is a consequence of the geometry of the cooling section and experimental conditions in the cited study and should not be generally extrapolated to all thermodenuder design and type of experiments.

Modeling by Saleh et al. (2011) showed that a a value $<0.7$ for the coupling dimensionless number $\mathrm{Cn}$, defined as the ratio between the particles and the walls re-condensation rate, implies a maximum re-condensation fraction of $10 \%$, as obtained from their transport model. In order to test whether the geometry or conditions in our model was above the range of negligible re-condensation defined by Saleh et al. (2011), we have calculated $\mathrm{Cn}$ values for our analysis. According to the formulations presented in Saleh et al. (2011), the value of $\mathrm{Cn}$ in our parametric study is $2.7-10$ for a mass loading of $400 \mu \mathrm{g} \mathrm{m}^{-3}\left(C^{*}=0.01 \mu \mathrm{g} \mathrm{m}^{-3}\right.$ and $\left.d_{\mathrm{p}} 0=100 \mathrm{~nm}\right)$. This value is well above the maximum $C n$ number defined by Saleh et al. (2011), for negligible re-condensation $(C n=0.7)$, explaining the significant re-condensation levels obtained with our model. For this $C n$ value, our model yields $80 \%$ re-condensation fraction, while Saleh et al. (2011) predicts a maximum re-condensation of $50 \%$. Although there is still a difference of $30 \%$ between our estimations, this may be due to the fact that our model presents radial resolution, while Saleh et al. (2011) solved a one dimension flow model that may not be as accurate to predict local condensation at the walls. In our study we have worked with geometries and conditions representative of some currently used thermodenuder designs, such as that of Huffman et al. (2008), which presents $\mathrm{Cn}$ values higher than 0.7 at high aerosol loadings (e.g. $C n=2-7.4$ for $100 \mathrm{~nm}$ particles at $400 \mu \mathrm{g} \mathrm{m}^{-3}$ and $C^{*}=0.01 \mu \mathrm{g} \mathrm{m}^{-3}$ ). It should be noted that whilst we acknowledge that thermodenuder geometries can be modified to reduce the effect of re-condensation (Saleh et al., 2011), the aim of our study is to analyse the issues derived from using current thermodenuder systems, even if their geometries are not optimum to minimise re-condensation issues.

The comprehensive analysis presented in this work suggests that re-condensation will be highly dependent on the particular experimental conditions employed and that caution should be taken, as re-condensation will not be negligible for every thermodenuder design. Laboratory studies should adopt measures to avoid re-condensation by reducing the cooling section tubing diameter and length when working at high aerosol mass loadings (Saleh et al., 2011). With these modifications a charcoal denuder may not be needed to control re-condensation (Saleh et al., 2011). Researchers who work with commercial thermodenuders that already incorporate a cooling/denuder section should be aware of the potential issues implied by re-condensation if they do not modify the configuration of their experimental systems. It should be noted that most available thermodenuder systems present a geometry which is problematic regarding re-condensation. An assessment on the potential of re-condensation to af-
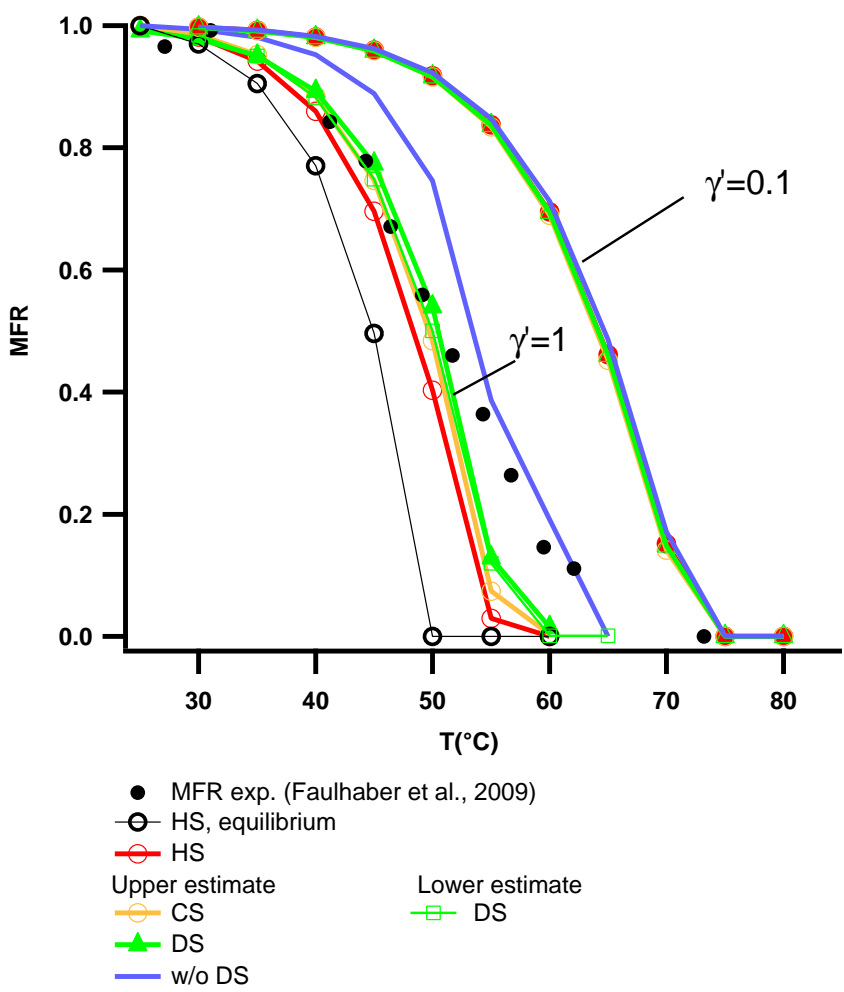

Fig. 7. Output thermograms and recondensation fraction for the heating section (HS), cooling section (CS), denuder section (DS) and equivalent configuration without denuder section (w/o DS), in a system with $200 \mathrm{~nm}$ butanedioic particles at $150 \mu \mathrm{g} \mathrm{m}^{-3}$ aerosol loading, in comparison with experiments by Faulhaber et al. (2009). The results show a best fit between observations and model for a kinetic coefficient close to unity. Upper estimate: upper estimate for re-condensation (no mass transfer to walls); lower estimate: lower estimate for re-condensation (equilibrium wall condensation).

fect aerosol volatility interpretation when using these current thermodenuder designs is presented in Sect. 7 of this paper.

\section{Re-condensation potential: selected cases}

\subsection{Single compounds: di-carboxylic acids}

The thermodenuder model was applied to simulate the evaporation of a set of single compound and multicomponent mixed aerosols in order to quantify the potential for recondensation. The cases selected are based on experimental measurements by Faulhaber et al. (2009), Grieshop et al. (2009) and Cappa and Wilson (2011), conducted at organic loadings between 70 and $650 \mu \mathrm{g} \mathrm{m}^{-3}$. The method applied consists on the iterative adjustment of the kinetic coefficient in order to obtain the best fit between the experimental data and the model predictions, with the best fit providing information on the degree of re-condensation. For comparison with the experimental measurements, the dimensions and operating conditions of the thermodenuder system 
relevant to each case were used to set the geometrical boundary conditions for the model.

Thermograms of di-carboxylic acids were modeled and compared with measurements by Faulhaber et al. (2009), as shown in Fig. 7. The potential for re-condensation, i.e. the difference between the lower and upper estimates for recondensation, is significant for this particular case, with a best agreement between succinic acid measurements and model predictions for an effective net evaporation coefficient of 1, in agreement with Cappa (2010). This value of kinetic coefficient holds for the lower and upper estimates of re-condensation. The derived kinetic coefficient is significantly higher than the value of $\sim 0.1$ determined by Saleh et al. (2011). The saturation concentration and enthalpy of vaporisation values used for the calculations were $3.57 \mu \mathrm{g} \mathrm{m}^{-3}$ and $124.9 \mathrm{~kJ} \mathrm{~mol}^{-1}$, respectively, which are the average values obtained from data provided by Chattopadhyay and Ziemann (2005), Bilde et al. (2003) and Davies and Thomas (1960). Chattopadhyay and Ziemann (2005) and Bilde et al. (2003) employed a TPTD and a TDMA method, respectively, to derive the vapor pressure of succinic acid using an assumption of kinetic coefficient equal to 1 . This assumption has been shown to be of low significance in TDMA studies, with changes in the vapor pressure estimation in less than $30 \%$ for variations of the kinetic coefficient in a range between 0.2 and 1 (Bilde et al., 2003). In the work by Davies and Thomas (1960) the vapor pressure was determined by means of an effusion method, without any assumption on the value of the evaporation coefficient. The vapor pressure derived from Davies and Thomas (1960) is in fact very similar to that from Bilde et al. (2003) (P25 of 4.23e-5 and 4.6e-5 Pa, respectively); thus, it is not evident that the derived evaporation coefficient could be pre-determined by the vapour pressure values used as input to the model. Further work is necessary in order to clarify differences between the kinetic coefficients determined in different studies.

\subsection{Multicomponent mixtures: lubricating oil and $\alpha$-pinene SOA}

Thermograms for lubricating oil aerosol and $\alpha$-pinene SOA were modeled to evaluate the potential for re-condensation occurring in experiments with multicomponent mixtures. The model was solved using volatility distributions provided by Pathak et al. (2007) and Grieshop et al. (2009), while the enthalpy of vaporisation as a function of the volatility was derived using equations from Epstein et al. (2009).

Figure $8 \mathrm{a}$ shows the modeled thermograms for lubricating oil using different net kinetic evaporation/condensation coefficients, together with experimental data (Cappa and Wilson, 2011). In agreement with results in Cappa and Wilson (2011), the values of kinetic coefficients that provide the best fit to the data fall in the range 0.1-1, with an optimum solution for $\gamma^{\prime}=0.3$. For this value of kinetic coefficient, an upper estimate of re-condensation yields re-condensation fractions of $\sim 50 \%$ if a charcoal denuder is not applied. As pointed out in previous work by Cappa and Wilson (2011), a value of evaporation coefficient of 0.3 for lubricating oil is in contrast with the low evaporation coefficient between $0.001-$ 0.0001 derived from dilution experiments by Grieshop et al. (2009). It has been argued that this discrepancy in the kinetic coefficient value may result from differences in the aerosol volatility because of using different particle generation methods (interactive comment on Cappa and Wilson, 2011). In order to analyse whether this is actually due to the aerosol generation technique, the evaporation model was applied to derive the net kinetic evaporation coefficient for thermodenuder experiments by Grieshop et al. (2009) conducted with the same lubricating oil aerosol sample that was used for their dilution chamber measurements (Fig. 8b). The specifications and operation of the thermodenuder system applied were those described in An et al. (2007) and Grieshop et al. (2009), with a HS centerline residence time of $16 \mathrm{~s}$ for a flow of $1 \mathrm{lpm}$ ( $32 \mathrm{~s}$ plug flow residence time). Note that for this thermodenuder system the denuder section was directly attached to the outlet of the heating section, thus only output thermograms for the heating section (HS) and denuder section (DS) are provided. Although the same lubricating oil aerosol sample was used in the thermodenuder and chamber experiments by Grieshop et al. (2009), we show that the net effective evaporation coefficient derived from their thermodenuder experiments was 0.3 (in agreement with thermodenuder measurement by Cappa and Wilson, 2011), while their chamber measurements yielded a kinetic coefficient of 0.001-0.0001. The slow evaporation rate of particles in Grieshop et al. (2009) dilution chamber may be induced by the release of material from the chamber walls (Matsunaga and Ziemann, 2010). Because of the potential artifact induced by the release of material from the chamber walls on particle evaporation, dilution experiments with standard Teflon walls do not seem to be an adequate methodology for conducting this type of studies. For this purpose, special dilution chambers provided with activated charcoal absorber should be used (Vaden et al., 2010).

In order to analyse the evaporation/re-condensation behaviour of $\alpha$-pinene SOA particles, experimental measurements by Cappa and Wilson (2011) were also simulated with the kinetic model. Assuming equal evaporation and re-condensation coefficients, a very low effective evaporation coefficient of 0.0001 is necessary to fit the model to the thermodenuder data (Cappa and Wilson, 2011). Although the slow evaporation of $\alpha$-pinene SOA aerosol has been attributed to the barrier to the diffusion process due to the amorphous structure of the particles, re-condensation of gas on the particle surface may not be affected by the particle phase. In such a case, the kinetic coefficient for recondensation could exhibit a higher value than that for the evaporation process. It should be noted that, because the kinetic limitation in reality may lie in the diffusion in the condensed phase through a viscous particle, the evaporation 

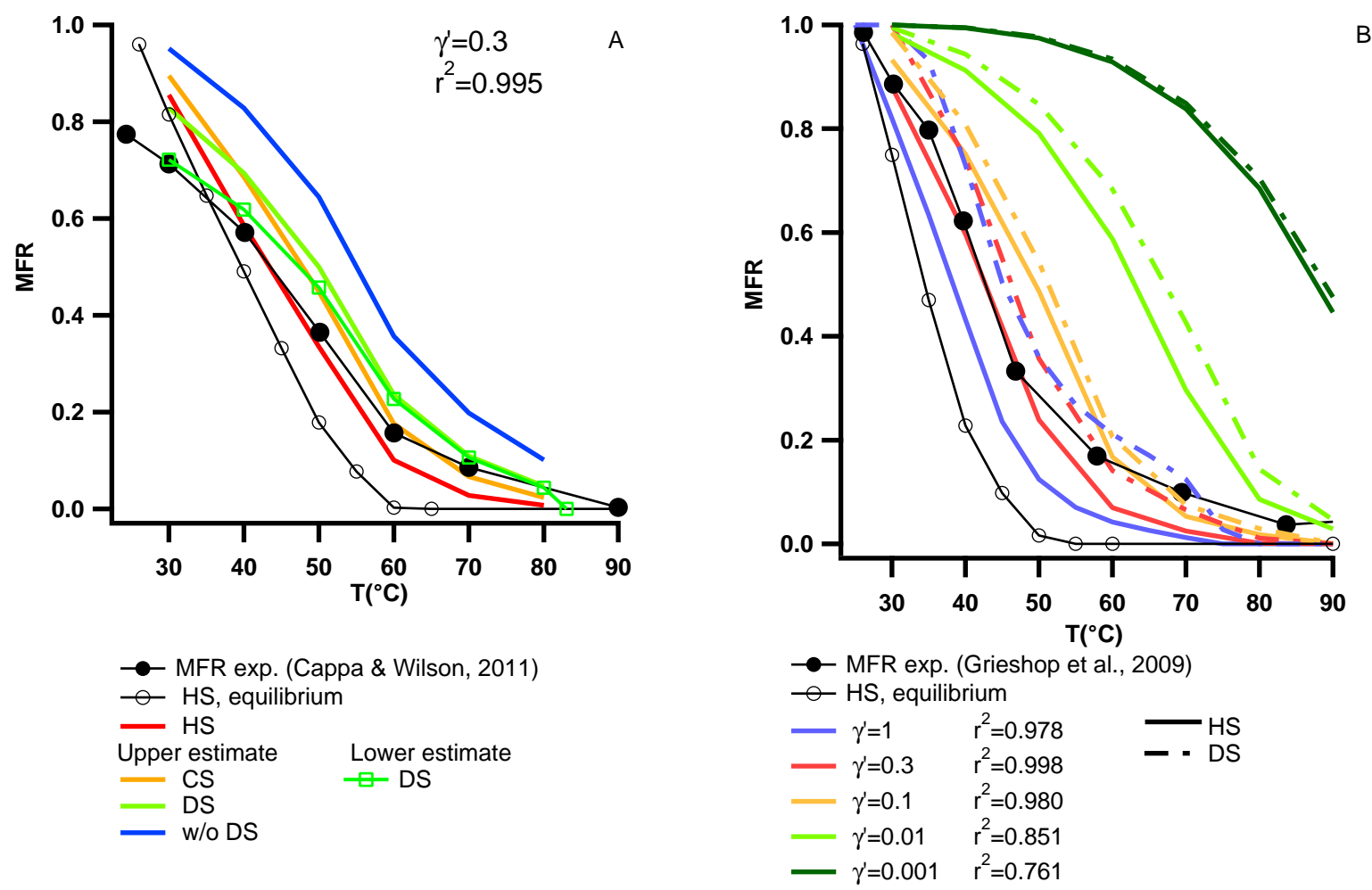

Fig. 8. (A) Output thermograms for heating section (HS), cooling section (CS) and denuder section (DS) in a system with $240 \mathrm{~nm}$ lubricating oil particles at $650 \mathrm{\mu g} \mathrm{m}^{-3}$ aerosol loading, in comparison with experiments by Cappa and Wilson (2011). The thermodenuder system was configured as described in Cappa and Wilson (2011). (B) Thermograms reproducing experiments by Grieshop et al. (2009) with 175 nm lubricating oil particles at $70 \mu \mathrm{g} \mathrm{m}^{-3}$ aerosol loading, in comparison with experimental results. Note that for this system the denuder section was directly attached at the outlet of the heating section and only output thermograms for the heating section (HS) and denuder section (DS) are provided. The specifications and operation of the thermodenuder system were as described in An et al. (2007) and Grieshop et al. (2009). In both type of experiments ( $\mathbf{A}$ and $\mathbf{B}$ ) the results show a best fit between observations and model for an effective kinetic coefficient between $0.1-1$, with an optimum for $\gamma^{\prime}=0.3$. Upper estimate: upper estimate for re-condensation (no mass transfer to walls); lower estimate: lower estimate for re-condensation (equilibrium wall condensation).

coefficient does not need to equal the condensation coefficient in the current model configuration. Figure 9 illustrates the results of the model for different evaporation coefficients $\left(\gamma_{\text {evap }}^{\prime}\right)$ between $0.0001-1$ and a re-condensation coefficient $\left(\gamma_{\text {cond }}^{\prime}\right)$ of unity. In agreement with Cappa and Wilson (2011), in the case of equal evaporation and recondensation coefficients the kinetic coefficient would have a value between $0.001-0.0001$ and re-condensation would be negligible. However, if the re-condensation and evaporation coefficients are allowed to be different, for a recondensation coefficient equal to 1 , the evaporation coefficient would have a value between $\sim 0.001-0.01$, with significant re-condensation occurring after the heating section. It should be noted that the assumption of a condensation kinetic coefficient of 1 provides for an upper limit for the evaporation coefficient, while analysis assuming equal kinetic coefficients for evaporation and re-condensation provides for a lower estimate of these coefficients. Further experimentation at lower aerosol loadings, where re-condensation is negligible, may be useful to test the hypothesis that the ef- fective kinetic coefficients for evaporation and condensation may present different values for amorphous solid particles.

The above analysis shows that the interpretation of the behaviour of the aerosol and the estimation of the degree of re-condensation is certainly dependent on the assumption whether the re-condensation process is affected by the amorphous solid phase of SOA. It should be remarked that care must be taken not to over-interpret the roles of evaporation and re-condensation coefficients when the kinetic limitation may be mainly due to the particle phase; however, the allowable discrepancy within experimental error of this coefficient may give an indication of the shrinkage and growth response to temperature changes of SOA particles.

\section{The relationship between $C^{*}$ and $T_{50}$}

The empirical calibration curve derived by Faulhaber et al. (2009) has been proposed as a method to derive vapour pressure values and volatility distributions from thermograms 

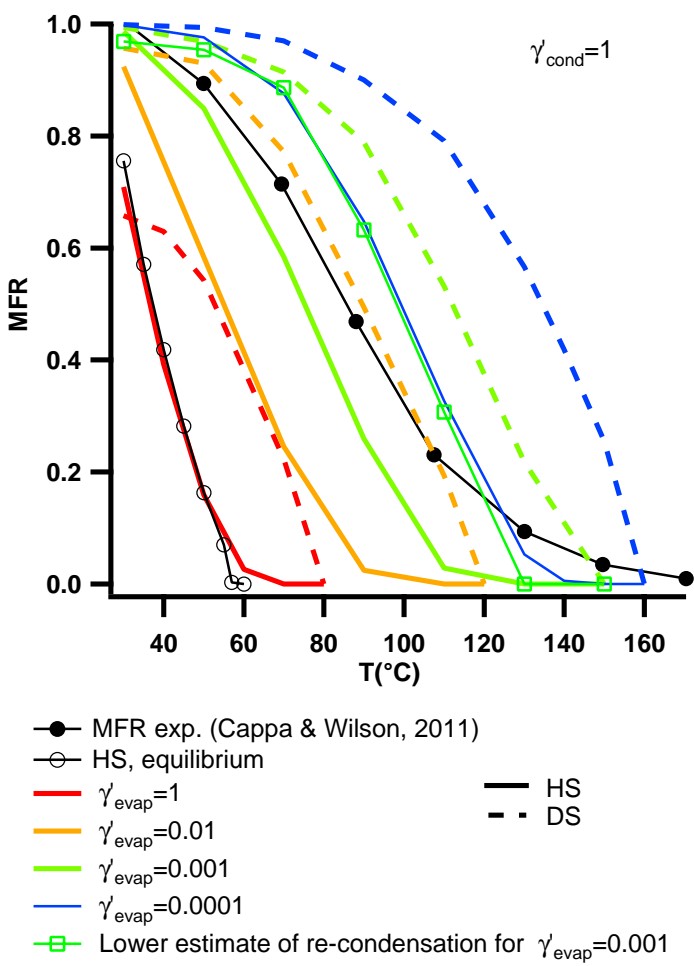

Fig. 9. Output thermograms for heating section (HS), cooling section (CS) and denuder section (DS) in a system with $92 \mathrm{~nm} \alpha$-pinene SOA particles at $500 \mathrm{\mu g} \mathrm{m}^{-3}$ aerosol loading, in comparison with experiments by Cappa and Wilson (2011). The calculations were conducted for different evaporation coefficients $\left(\gamma_{\text {evap }}^{\prime}\right)$ and a recondensation coefficient ( $\gamma_{\text {cond }}^{\prime}$ ) equal to unity, under the assumption that the particle phase does not affect the re-condensation process. The results show a best fit between observations and model for an evaporation coefficient between 0.01-0.001, with an optimum for $\gamma^{\prime}=0.01$. Data represent the upper estimate for re-condensation unless otherwise stated.

(Cappa and Jimenez, 2010). This curve, which is based on an empirical relationship determined between the vapour pressure and the temperature at which $50 \%$ of the aerosol mass evaporates $\left(T_{50}\right)$, was derived from a limited set of semivolatile organic compounds at $\sim 150 \mu \mathrm{g} \mathrm{m}^{-3}$ aerosol loading (Faulhaber et al., 2009). Hence, the validity of this calibration curve for compounds and conditions diverging from those used for the calibration remains to be proven. In this section, insights on the theoretical interpretation of the relationship comprising this calibration curve and on its validity for predicting the volatility of a variety of compounds are provided.

Following similar reasoning to Saleh et al. (2008), the change of particle phase mass resulting from the evaporation/condensation of a compound i by heating/cooling from an initial reference state 0 to a final state " $\mathrm{f}$ ", is considered equal to the change of gas phase mass and defined, including the kelvin effect $\left(K_{0(\mathrm{f})}\right)$, as:

$\Delta c_{\mathrm{p}, i}=-\Delta c_{\mathrm{g}, i}=C_{i, 0}^{*} x_{i, 0} K_{0}-C_{i, \mathrm{f}}^{*} x_{i, \mathrm{f}} K_{\mathrm{f}}$

where $C_{i, 0}^{*}$ and $C_{i, \mathrm{f}}^{*}$ are the saturation concentration at the reference temperature (i.e. $298 \mathrm{~K}$ ) and at the final temperature state expressed in terms of mass, respectively, and $x_{i, 0}$ and $x_{i, \mathrm{f}}$ are the mass fractions of component $i$ in the particle phase at the reference and final states, respectively.

The Clausius-Clapeyron equation defines the vaporisation enthalpy $\left(H_{\mathrm{v}, i}\right)$ and saturation concentration relationship under the assumption of enthalpy constant over the temperature range as:

$C_{i, \mathrm{f}}^{*}=C_{i, 0}^{*} \exp \left[-\frac{\Delta H_{\mathrm{v}, i}}{R}\left(\frac{1}{T_{\mathrm{f}}}-\frac{1}{T_{0}}\right)\right] \frac{T_{0}}{T_{\mathrm{f}}}$

Using the above equation, the change in particle mass can be defined from Eq. (12) as:

$$
\begin{aligned}
& -\Delta c_{\mathrm{p}, i}=C_{i, 0}^{*} x_{i, 0} K_{0} \\
& \left(\frac{x_{i, \mathrm{f}}}{x_{i, 0}} \frac{K_{\mathrm{f}}}{K_{0}} \frac{T_{0}}{T_{\mathrm{f}}} \exp \left(-\frac{\Delta H_{\mathrm{v}, i}}{R}\left(\frac{1}{T_{\mathrm{f}}}-\frac{1}{T_{0}}\right)\right)-1\right)
\end{aligned}
$$

By expressing the change in total particle mass in terms of $\mathrm{C}_{\mathrm{OA}}$ difference, the previous equation leads to:

$$
\begin{aligned}
& C_{\mathrm{OA} i, 0}-C_{\mathrm{OA} i, \mathrm{f}}=C_{i, 0}^{*} x_{i, 0} K_{0} \\
& \left(\frac{x_{i, \mathrm{f}}}{x_{i, 0}} \frac{K_{\mathrm{f}}}{K_{0}} \frac{T_{0}}{T_{\mathrm{f}}} \exp \left(-\frac{\Delta H_{\mathrm{v}, i}}{R}\left(\frac{1}{T_{\mathrm{f}}}-\frac{1}{T_{0}}\right)\right)-1\right),
\end{aligned}
$$

which divided by $C_{\mathrm{OAi}, 0}$ yields:

$$
\begin{aligned}
& 1-\frac{C_{\mathrm{OA} i, \mathrm{f}}}{C_{\mathrm{OA} i, 0}}=\frac{C_{i, 0}^{*} x_{i, 0} K_{0}}{C_{\mathrm{OAi}, 0}} \\
& {\left[\frac{x_{i, \mathrm{f}}}{x_{i, 0}} \frac{K_{\mathrm{f}}}{K_{0}} \frac{T_{0}}{T_{\mathrm{f}}} \exp \left(-\frac{\Delta H_{\mathrm{v}, i}}{R}\left(\frac{1}{T_{\mathrm{f}}}-\frac{1}{T_{0}}\right)\right)-1\right]}
\end{aligned}
$$

Using the definition of mass fraction remaining for a component i, $\mathrm{MFR}_{i}=C_{\mathrm{OA} i, \mathrm{f}} / C_{\mathrm{OA} i, 0} \mathrm{Eq}$. (17) leads to the following expression for $C_{i, 0}^{*}$ :

$$
\begin{aligned}
& C_{i, 0}^{*}=\frac{1}{K_{0}} C_{\mathrm{OA}, 0}\left(1-\mathrm{MFR}_{i}\right) \\
& {\left[\frac{x_{i, \mathrm{f}}}{x_{i, 0}} \frac{K_{\mathrm{f}}}{K_{0}} \frac{T_{0}}{T_{\mathrm{f}}} \exp \left(-\frac{\Delta H_{\mathrm{v}, i}}{R}\left(\frac{1}{T_{\mathrm{f}}}-\frac{1}{T_{0}}\right)\right)-1\right]^{-1}}
\end{aligned}
$$

Assuming equal density of the organic compounds in the particle, the mass fraction remaining is equal to a volume fraction remaining and the kelvin term ratio can be expressed as:

$$
\frac{K_{\mathrm{f}}}{K_{0}}=\exp \left[\frac{4 M_{i} \sigma\left(T_{0}-T_{\mathrm{f}} \mathrm{MFR}^{1 / 3}\right)}{\rho_{i} R T_{0} T_{\mathrm{f}} d_{\mathrm{p}_{0}} \mathrm{MFR}^{1 / 3}}\right]
$$

with the Kelvin term $K_{0}$ in Eq. (18) defined as:

$$
K_{0}=\exp \left(\frac{4 M_{i} \sigma}{R T_{0} \rho d_{\mathrm{p}_{0}}}\right)
$$


Using the definition of total mass fraction remaining, $\mathrm{MFR}=C_{\mathrm{OA}, f} / C_{\mathrm{OA}, 0}$, the mass fraction ratio can be expressed as:

$\frac{x_{i, \mathrm{f}}}{x_{i, 0}}=\frac{\mathrm{MFR}_{i}}{\mathrm{MFR}}$

and Eq. (17) can be re-written as:

$$
\begin{aligned}
& C_{i, 0}^{*}=\frac{1}{K_{0}} C_{\mathrm{OA}, 0}\left(1-\mathrm{MFR}_{i}\right) \\
& {\left[\frac{\mathrm{MFR}_{i}}{\mathrm{MFR}} \frac{K_{\mathrm{f}}}{K_{0}} \frac{T_{0}}{T_{\mathrm{f}}} \exp \left(-\frac{\Delta H_{\mathrm{v}, i}}{R}\left(\frac{1}{T_{\mathrm{f}}}-\frac{1}{T_{0}}\right)\right)-1\right]^{-1}}
\end{aligned}
$$

For $\mathrm{MFR}_{i}=0.5, T_{\mathrm{f}}=T_{50}$ and the saturation concentration $C_{0}^{*}$ for a single component $\left(\mathrm{MFR}=\mathrm{MFR}_{i}\right)$ is formulated as:

$$
\begin{aligned}
& C_{0}^{*}= \\
& \frac{0.5}{K_{0}} C_{\mathrm{OA}, 0}\left[\frac{K_{\mathrm{f}}}{K_{0}} \frac{T_{0}}{T_{50}} \exp \left(-\frac{\Delta H_{\mathrm{v}, i}}{R}\left(\frac{1}{T_{50}}-\frac{1}{T_{0}}\right)\right)-1\right]^{-1}
\end{aligned}
$$

In an analogous manner, the expression of $\mathrm{C}_{i}^{*}$ for a multicomponent mixture at $\mathrm{MFR}_{i}=0.5$ is given by:

$$
\begin{aligned}
& C_{i, 0}^{*}=\frac{0.5}{K_{0}} C_{\mathrm{OA}, 0} \\
& {\left[\frac{0.5}{\mathrm{MFR}} \frac{K_{\mathrm{f}}}{K_{0}} \frac{T_{0}}{T_{50, i}} \exp \left(-\frac{\Delta H_{\mathrm{v}, i}}{R}\left(\frac{1}{T_{50, i}}-\frac{1}{T_{0}}\right)\right)-1\right]^{-1}}
\end{aligned}
$$

Equations (22) and (23) provide expressions relating $C_{0}^{*}$ and $1 / T_{50}$, which will be compared with the empirical equation by Faulhaber et al. (2009). It should be noted that because the derived equations are based on the definition of particle mass evaporated between equilibrium states, the obtained expressions are constrained to equilibrium thermograms. Deviation due to the curvature effect (i.e. Kelvin term) can be neglected in the above equations, as shown in the following sensitivity analysis. The sensitivity of the equilibrium calibration curve to the aerosol properties defined within the term $K_{\mathrm{f}} / K_{0}$, was evaluated at constant aerosol loading and heat of vaporisation for $d_{\mathrm{p}_{0}}$ between $30-200 \mathrm{~nm}$, density between 800 $2000 \mathrm{~kg} \mathrm{~m}^{-3}$, molar mass between $100-400 \mathrm{~g} \mathrm{~mol}^{-1}$ and surface tension between $0.05-0.073 \mathrm{mN} \mathrm{m}^{-1}$. This sensitivity analysis yielded a very low influence of the above particle properties on the calibration curve, with maximum deviations of $2{ }^{\circ} \mathrm{C}$ in the estimation of $T_{50}$. Because of the low sensitivity of the calibration curve to the kelvin term, both $K_{\mathrm{f}} / K_{0}$ and $K_{0}$ were dropped from the equation and assumed to be $\sim 1$ in subsequent calculations.

Figure 10 shows $\log \left(P_{0}\right)$ vs. $1 / T_{50}$ values derived using the single component theoretical expression (Eq. 22), applied for the calibration compound in Faulhaber et al. (2009) (i.e. dicarboxylic acids, oleic acid and DOS aerosol). The agreement between the experimental data and theoretical results, reveals that the empirical equation derived by Faulhaber et al. (2009) is in fact the equilibrium relationship between $C_{0}^{*}$

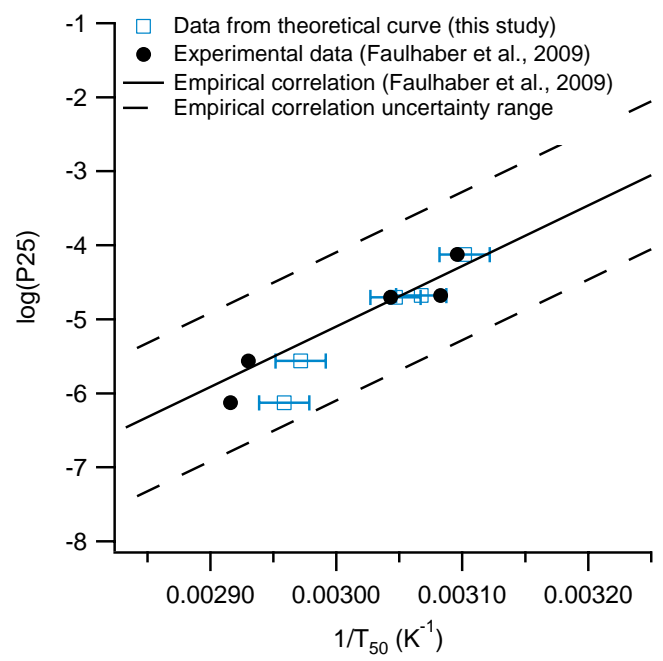

Fig. 10. Relationship between $\log P_{25}$ and $1 / T_{50}$ derived with Eq. (22) for the organic compounds used in the calibration by Faulhaber et al. (2009), in comparison with experimental data. The error bars in the theoretical calculation denotes the uncertainty in the aerosol loading (100-200 $\mathrm{g} \mathrm{m}^{-3}$ ).

and $1 / T_{50}$ in Eq. (22), specifically defined for the selected calibration compounds at $C_{\mathrm{OA}, 0}=150 \mu \mathrm{g} \mathrm{m}^{-3}$. Indeed, when averaging the properties of enthalpy of vaporisation, molar mass and vapour pressure of the calibration compounds the equilibrium theoretical equation leads to the expression $\log \left(P_{0}\right)=7376 T_{50}^{-1}-27.73$, which is strikingly similar to the empirical expression $\log \left(P_{0}\right)=8171 T_{50}^{-1}-29.61$, derived by Faulhaber et al. (2009).

The variation of the calibration curve as a function of $C_{\mathrm{OA}, 0}$ for organic compounds of different homologous groups was analysed in order to evaluate the influence of the experimental conditions on the $C_{0}^{*}-1 / T_{50}$ relationship. Figure 11 illustrates the theoretical calibration curve for aerosol loadings between $10-400 \mu \mathrm{g} \mathrm{m}^{-3}$ for different organic groups, together with experimental data from Faulhaber et al. (2009). The thermodynamic data used as input for the analysis was obtained from diverse literature sources (Chickos and Hanshaw, 1997; Kulikov et al., 2001; Chattopadhyay and Ziemann, 2005; Donahue et al., 2011). Results in Fig. 11 show that the data for the different groups lay on the same curve, with a relatively good agreement between the empirical calibration and the theoretical curve data for $C_{\mathrm{OA}, 0}$ between $150-400 \mu \mathrm{g} \mathrm{m}^{-3}$ and a more significant deviation between the empirical and theoretical curves for decreasing aerosol loading. The fact that the different type of compounds lay on the same curve at constant aerosol loading, results from the vaporisation enthalpy and $C_{0}^{*}$ data following a relationship which is found to be equivalent to that provided by Epstein et al. (2009):

$\Delta H_{\mathrm{v}, i}=-11 \log \left(C_{i}^{*}\right)+129$ 
Figure 11 shows that, because of the dependence of the equilibrium calibration curve on the organic aerosol loading, particle volatility would be underestimated by more than one order of magnitude when applying the empirical calibration at atmospheric aerosol levels of $\sim 10 \mu \mathrm{g} \mathrm{m}^{-3}$, with respect to the equilibrium equation. It should be noted, however, that in a real thermodenuder with residence time up to $30 \mathrm{~s}$, equilibrium will not be attained at low aerosol loadings and therefore the $C^{*}$ vs. $1 / T_{50}$ curve will deviate from the equilibrium theoretical calculation. Because of the reduced uncertainty and inclusion of all the factors affecting the relationship, the mathematical combination of the theoretical calibration curve defined in Eqs. (22) and (23) and Epstein et al. (2009) equation (Eq. 24) constitutes a more accurate approach for the estimation of saturation concentrations than the empirical expression of Faulhaber et al. (2009), when applied at equilibrium conditions that may be achieved in laboratory experiments at high aerosol loadings.

It has been shown in previous work (Riipinen et al., 2010; Saleh et al., 2011) and in Sect. 4 of this study that equilibrium might not be attained in thermodenuders measurements at low aerosol loadings and for low effective evaporation coefficients. Hence, underestimation of particles volatility using the equilibrium calibration curve is expected at kineticcontrolled conditions. Figure 12 illustrates the deviations expected with respect to the theoretical calibration curve due to equilibrium not being completely reached in the thermodenuder measurements. At kinetic-controlled conditions, $T_{50}$ would be larger than the corresponding value at equilibrium, leading to non-equilibrium calibration curves laying on the left of the equilibrium curve. The deviations from the equilibrium curve due to low aerosol loading and low evaporation coefficients have been depicted in Fig. 12. Deviation of $T_{50}$ up to $20-30{ }^{\circ} \mathrm{C}$ from the equilibrium value fortuitously places the calibration curve within the region of uncertainty of the empirical equation. Larger deviations from equilibrium situates the calibration curve at significant distance from the empirical and equilibrium curves, invalidating the general application of the empirical and theoretical curves for estimating the volatility of compounds from nonequilibrium thermograms.

The general expression in Eq. (23) can also be used to derive equilibrium thermograms, i.e. MFR as a function of the temperature, if the volatility distribution of the aerosol is known, by considering that the total mass fraction remaining can be expressed as a function of $\mathrm{MFR}_{i}$ as:

$\operatorname{MFR}=\sum_{i=1}^{n} x_{i, 0} \operatorname{MFR}_{i}$

where $x_{i, 0}$ is the mass fraction of the compound in the particle at the reference state. According to Eq. (23), equilibrium thermograms would only be determined by the volatility and vaporisation enthalpy of the individual compounds in the aerosol composition and by the specific aerosol mass
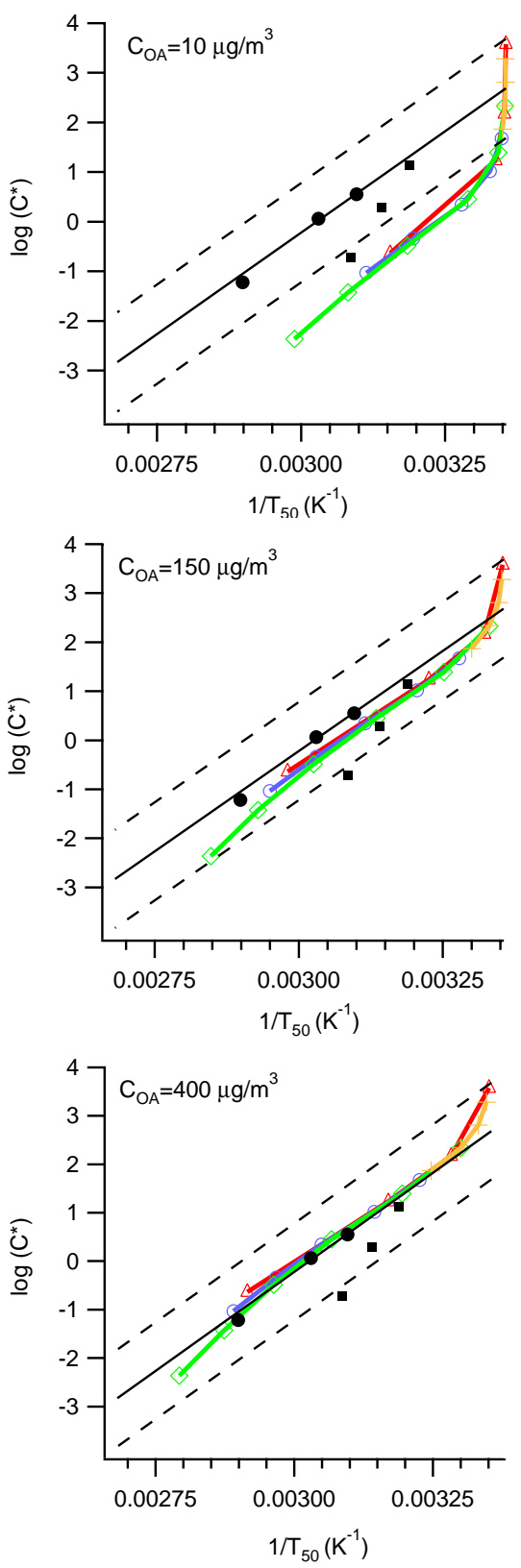

- Monocarboxylic acids, exp.

- Dicarboxylic acids, exp. (Faulhaber et al., 2009)

- Empirical calibration (Faulhaber et al., 2009)

_ - Empirical equation uncertainty range

Theoretical calibration curve for:

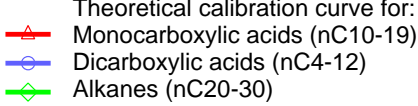

$\neg$ Alkanes (nC20-30)

+ Alcohols (nC13-16)

Fig. 11. Theoretical relationship between $C_{0}^{*}$ and $1 / T_{50}$ for different organic compounds, as derived from Eq. (22) at different aerosol mass loadings. The empirical and theoretical curves overlap for high aerosol loadings, while deviation between the curves is expected for low atmospheric aerosol loadings. 
loading conditions. Under the assumption that thermograms are not modified after leaving the heating section (i.e. negligible re-condensation) and negligible curvature effect, Eq. (23) implies that identical thermograms should be obtained with different thermodenuders for the same aerosol sample and initial aerosol loadings, if equilibrium is attained. In contrast, dependence of thermograms on additional factors such as particle size and evaporation coefficient is expected at kinetically-controlled evaporation conditions (Faulhaber et al., 2009; Riipinen et al., 2010).

The equilibrium curve defined in Eq. (23) can be applied not only to interpret thermodenuder measurements but also to analyse the change in aerosol mass loading upon changes in the atmospheric temperature assuming that the aerosol reaches equilibrium. The combination of Eqs. (23), (24) and (25) constitutes a system which allows for the calculation of the variations in the aerosol mass upon changes in the temperature, if the composition of the aerosol at a reference temperature is known. This is in fact an equivalent method to using the partitioning theory in combination with the Clausius-Clapeyron equation. This approach was used to explore the variation of the equilibrium aerosol mass with changes in the temperature and dilution ratio with respect to the initial aerosol loading, in comparison with kineticallycontrolled evaporation/condensation simulations performed with the kinetic model. It should be noted that these calculations are presented with an illustrative purpose to infer the variations of aerosol mass under the assumption of equilibrium or kinetically-controlled conditions and not to provide insights on the effect of complex atmospheric processing on aerosol partitioning. Figure 13 (top) illustrates the change of the total mass ratio $\mathrm{COA}_{\mathrm{f}} / \mathrm{COA}_{0}$ for lubricating oil and $\alpha$ pinene SOA aerosols, taking as a reference a temperature of $25^{\circ} \mathrm{C}$ and an aerosol loading of $20 \mu \mathrm{g} \mathrm{m}^{-3}$. For lubricating oil it was considered that equilibrium is attained in a short timescale, while for the case of amorphous solid $\alpha$-pinene SOA, calculations are provided for (1) equilibrium conditions, which implies that the condensation coefficient is high enough as to achieve equilibrium in a short time-scale, and (2) for non-equilibrium conditions, assuming $d_{\mathrm{p} 0}=100 \mathrm{~nm}$ and an effective kinetic coefficient $\gamma_{\text {cond }}^{\prime}=\gamma_{\text {evap }}^{\prime}=0.00055$ (mean value between 0.001-0.0001, optimum range found when $\gamma_{\text {cond }}^{\prime}=\gamma_{\text {evap }}^{\prime}($ Cappa and Wilson, 2011)). Because the condensation process would be dependent on the time scale for the kinetically-controlled case, the kinetic model was applied to calculate the change in the particle mass due to cooling from $25^{\circ} \mathrm{C}$ for time scales of $1 \mathrm{~h}, 3 \mathrm{~h}$ and $5 \mathrm{~h}$. The use of different coefficients for condensation and evaporation is aimed to represent the limitation to the kinetic rate in one direction or another. It should be noted that at the molecular limit, the differences in the coefficients used in our analysis may lead to unphysical behaviour; however this approach is still useful to analyse the behaviour when the evaporation process is inhibited. The equilibrium results provided
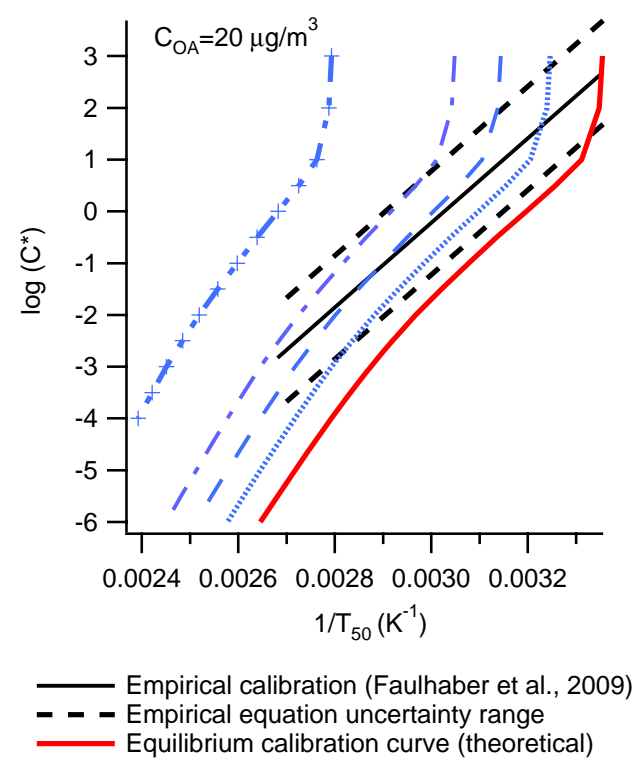

Calibration curves at kinetically controlled conditions: $\gamma^{\prime}=1$

$-\quad-\gamma^{\prime}=0.1$

- - $\gamma^{\prime}=0.01$

$-t=-\gamma^{\prime}=0.001$

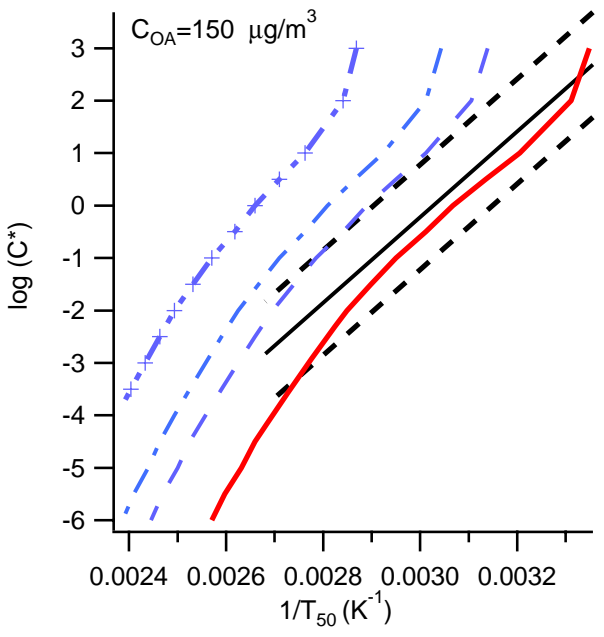

— Empirical calibration (Faulhaber et al., 2009)

- Empirical equation uncertainty range

Equilibrium calibration curve (theoretical)

Calibration curves at kinetically controlled conditions:

- $\quad \gamma^{\prime}=0.1$

- $\gamma^{\prime}=0.01$

$+\gamma^{\prime}=0.001$

Fig. 12. Deviation of the calibration curve due to equilibrium not being attained in thermodenuder measurements at two different aerosol loadings. $T_{50}$ deviations up to $\sim 20-30{ }^{\circ} \mathrm{C}$, with respect to equilibrium, situate the calibration curve within the uncertainty region of the empirical formulation. Further difference with respect to equilibrium (particularly for $\gamma^{\prime}<0.01$ ) leads to significant deviation of the calibration curve with respect to the empirical and theoretical curves. 
represent the case with $\gamma_{\text {cond }}^{\prime}=\gamma_{\text {evap }}^{\prime}=1$ for the considered time scales.

The difference in composition between lubricating oil and $\alpha$-pinene SOA in the upper volatility bins leads to a large difference regarding the equilibrium aerosol formation upon cooling between these two types of aerosols (particularly due to a mass fraction of 0.1 for $C^{*}=10^{4} \mu \mathrm{g} \mathrm{m}^{-3}$ in the lubricating aerosol composition versus a mass fraction of 0.6 for $\alpha$-pinene SOA). The results also reveal a very different aerosol forming potential for $\alpha$-pinene SOA depending on the assumption of condensation coefficient. The large uncertainty in the prediction of the amount of aerosol formed from amorphous solid SOA points at the necessity of further studying whether growth of glass-like particles during cooling would be retarded by the particle phase as shrinkage may be assumed to be.

The sensitivity to the assumption of effective kinetic evaporation coefficient has also been explored for the aerosol mass change resulting from dilution-induced evaporation of amorphous solid SOA particles. In a similar manner to the above analysis, calculations were conducted under the assumptions of (1) equilibrium conditions (i.e. kinetic coefficients equal to unity for the time scales considered here or any kinetic coefficient values as long as equilibrium is attained), (2) non-equilibrium, with $\gamma_{\text {evap }}^{\prime}=\gamma_{\text {cond }}^{\prime}=0.00055$ and (3) non-equilibrium with $\gamma_{\text {evap }}^{\prime}=0.055$ (optimum value for $\left.\gamma_{\text {cond }}^{\prime}=1\right)$. Figure $13 \mathrm{~b}$ shows the results of this analysis as the ratio between the aerosol mass remaining after dilution (corrected for the dilution ratio) and the initial aerosol mass, which is equivalent to the mass change ratio due to particle evaporation. As expected, amorphous solid SOA (cases with $\gamma_{\text {evap }}=0.0055$ and $\left.\gamma_{\text {evap }}^{\prime}=0.00055\right)$ exhibits a much lower sensitivity to dilution than what it is predicted by equilibrium partitioning. In particular, the model points at an underestimation in the aerosol mass remaining in a factor from 5 to 10 , if partitioning equilibrium theory is applied. It should be noted that the estimation of particle mass evaporated with the kinetic model is also highly sensitive to the assumption of effective evaporation coefficient, and that a better constraint of this value is required to adequately predict the changes in aerosol mass upon dilution.

\section{Derivation of volatility distributions from thermodenuder measurements}

Evaporation profiles from thermodenuder measurements can be applied to derive the volatility distribution using the method of Faulhaber et al. (2009). This method involves using the calibration curve between $C_{0}^{*}$ and $1 / T_{50}$, together with the thermogram measurements for the subsequent derivation of the particle fraction belonging in each $C_{0}^{*}$ volatility bin (Faulhaber et al., 2009). In this section diverse thermograms are used to derive the volatility distributions using the equilibrium equation derived in the present study, the empirical

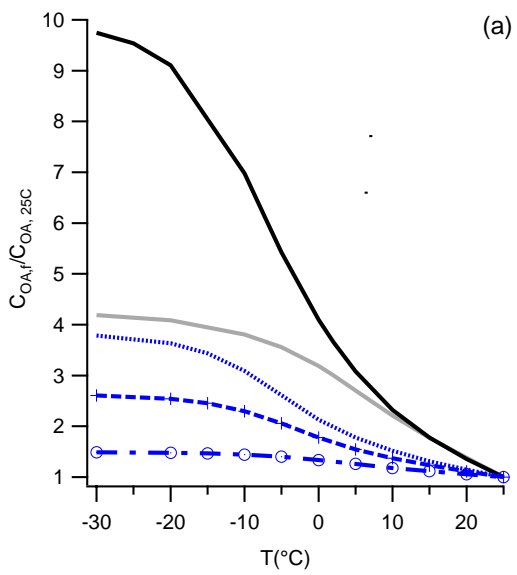

(a)

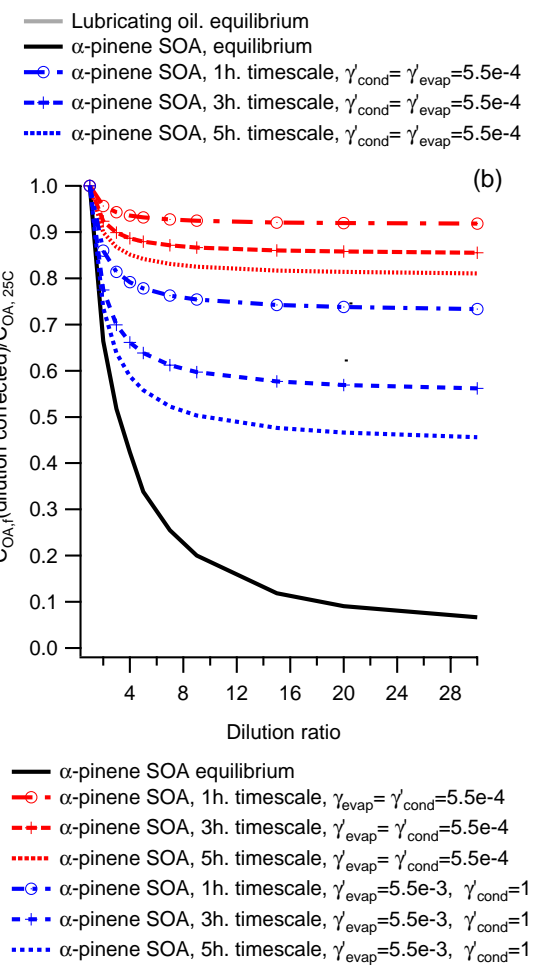

Fig. 13. (a) Condensed mass forming potential of lubricating oil and $\alpha$-pinene SOA resulting from cooling from initial conditions at $25^{\circ} \mathrm{C}$ and $20 \mu \mathrm{g} \mathrm{m}^{-3}$ aerosol loading. For the $\alpha$-pinene SOA aerosol, the cases presented are (1) equilibrium, assuming that gas condensation is not affected by the particle phase and (2) nonequilibrium conditions with $\gamma_{\text {cond }}^{\prime}=\gamma_{\text {evap. }}$. A strong difference is obtained in the particle mass change estimation, depending on the assumption of condensation being or not affected by the particle amorphous solid state. (b) Change in $\alpha$-pinene SOA aerosol mass resulting from dilution-induced evaporation for the cases of (1) equilibrium (2) non-equilibrium with $\gamma_{\text {evap }}^{\prime}=\gamma_{\text {cond }}^{\prime}$ and (3) nonequilibrium with $\gamma_{\text {evap }}^{\prime}=5 \mathrm{e}-3$ and $\gamma_{\text {cond }}^{\prime}=1$. While the equilibrium partitioning calculations significantly overestimate the amount of amorphous solid aerosol mass evaporated due to dilution, a large difference in the estimation of aerosol mass is obtained depending on the assumption of effective evaporation coefficient. 
calibration by Faulhaber et al. (2009) and the kinetic model approach applied by Cappa and Jimenez (2010). The derived distributions are compared with those obtained by applying aerosol mass fraction parameterisations determined from chamber experiments by Pathak et al. (2007) and Grieshop et al. (2009) for the aerosols on study. It has been previously discussed by Saleh et al. (2011) that the use of thermograms could be misleading in the case that mass fraction remaining (MFR) values are directly compared to interpret particles volatility (e.g. comparison of MFR values at constant temperature), since MFR values depend on the initial aerosol mass loading. It should be noted that this issue is overcome in the present study by applying methods which account for the dependence of thermograms on the initial aerosol mass loading.

\subsection{Calibration curve approach: empirical and theoretical equations}

The volatility distribution for lubricating oil and $\alpha$-pinene SOA was derived from thermogram measurements by Grieshop et al. (2009) and Cappa and Wilson (2011) (Fig. 14), using the empirical and theoretical calibration curves following the method described in Faulhaber et al. (2009). In addition, in order to estimate the potential deviation in the prediction due to re-condensation, thermograms after the heating section were modeled using the kinetic model and subsequently used to derive the volatility distribution.

Figure 14 shows the lubricating oil aerosol volatility distribution as determined from thermodenuder measurements at two different aerosol loadings. It should be noted that the upper volatility bin with this method is restricted to $C_{0}^{*} \geq$ $100 \mu \mathrm{g} \mathrm{m}^{-3}$, which is the maximum volatility limit for the possible estimation of $T_{50}$ above ambient temperature. For the case of $70 \mu \mathrm{g} \mathrm{m}^{-3} \mathrm{~m}$ (Fig. 14a) there is a reasonable agreement between the ideal volatility set distribution and that predicted using Faulhaber et al. (2009) empirical curve, with little effect of re-condensation in this estimation. In contrast, the aerosol volatility is significantly underestimated when using the equilibrium curve. This deviation is due to the fact that, for this aerosol loading, the thermogram is not at equilibrium; hence, $T_{i, 50}$ exhibits values larger than those in the equilibrium thermogram, resulting in a calibration curve at the left of the equilibrium theoretical curve. Figure S7 shows how the resulting calibration curve fortuitously lays in the proximity of the empirical equation, resulting in a better prediction with respect to the equilibrium curve. It should be noted that although the prediction using the empirical curve is valid in this case, the fact that the calibration curve falls over the empirical curve is merely fortuitous and it cannot be concluded that the empirical approximation would be valid at other experimental conditions.

At $650 \mu \mathrm{g} \mathrm{m}^{-3}$ aerosol loading (Fig. 14, bottom), both the empirical and equilibrium curves approach the volatility distribution derived from literature data. At this high aerosol
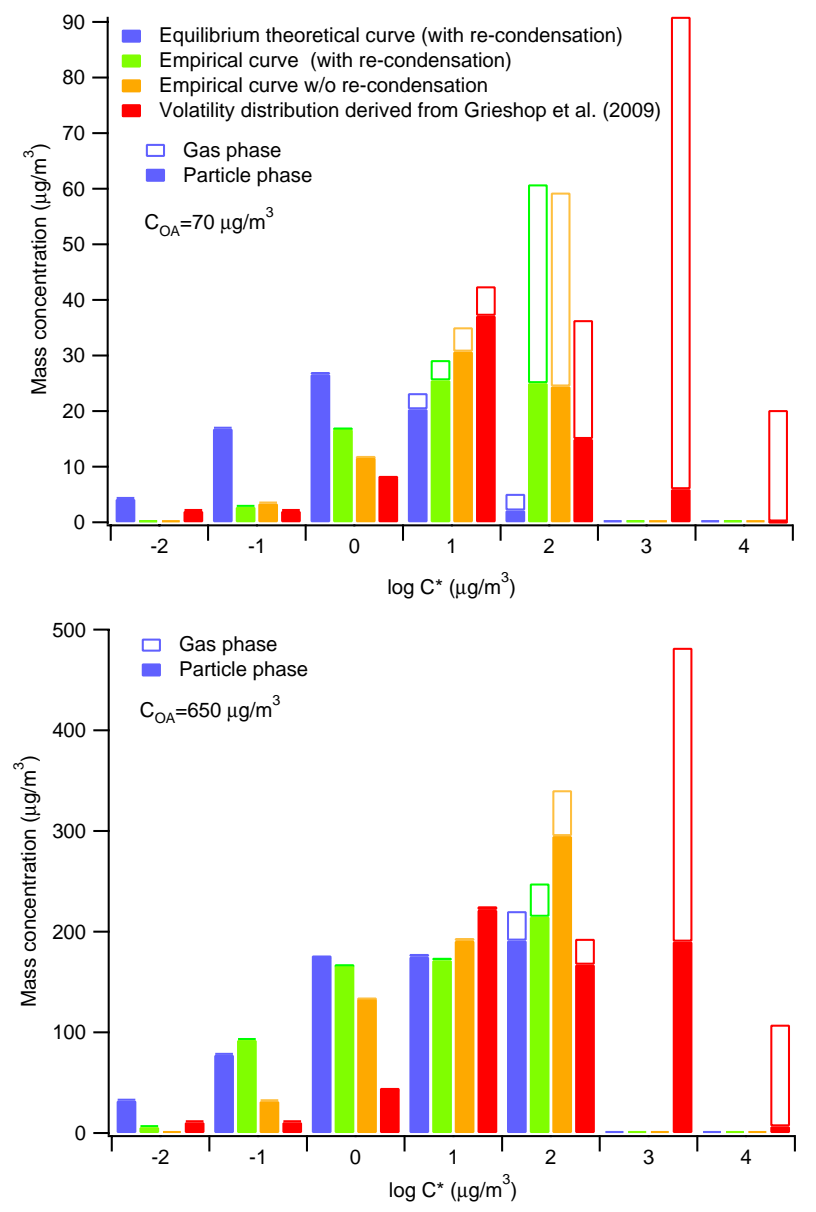

Fig. 14. Volatility distributions derived from lubricating oil thermograms at 70 and $650 \mu \mathrm{g} \mathrm{m}^{-3}$ aerosol loading, using the equilibrium and empirical calibration curve approach. For $70 \mu \mathrm{g} \mathrm{m}^{-3}$ (a) the thermogram considerably deviates from equilibrium (Fig. 8 and S5), thus, resulting in the equilibrium calibration approach underestimating the aerosol volatility. The empirical calibration provides a better agreement in this case, due to the calibration curve fortuitously laying on the empirical calibration curve (Fig. S5). For the highest aerosol loading (b), the thermograms are close to equilibrium (Fig. 8 and S5) and the predictions approach the distribution derived using the volatility basic-set distribution by Grieshop et al. (2009).

mass, the empirical and equilibrium curve are close to each other (Fig. S7), and evaporation equilibrium is close to be attained (Fig. 8a), which leads to a better agreement between the distribution derived from literature data (Grieshop et al., 2009) and the predictions. The overestimation in the aerosol mass obtained for the lower volatility bins with respect to (Grieshop et al., 2009) distribution is possibly due to the fact that Faulhaber et al. (2009) method is restricted to volatility bins with $C^{*}<100 \mu \mathrm{g} \mathrm{m}^{-3}$, which at the very high aerosol loading of this case, may result in the mass from the upper volatility compounds being distributed between the lower volatility bins. This reveals a 
(a)
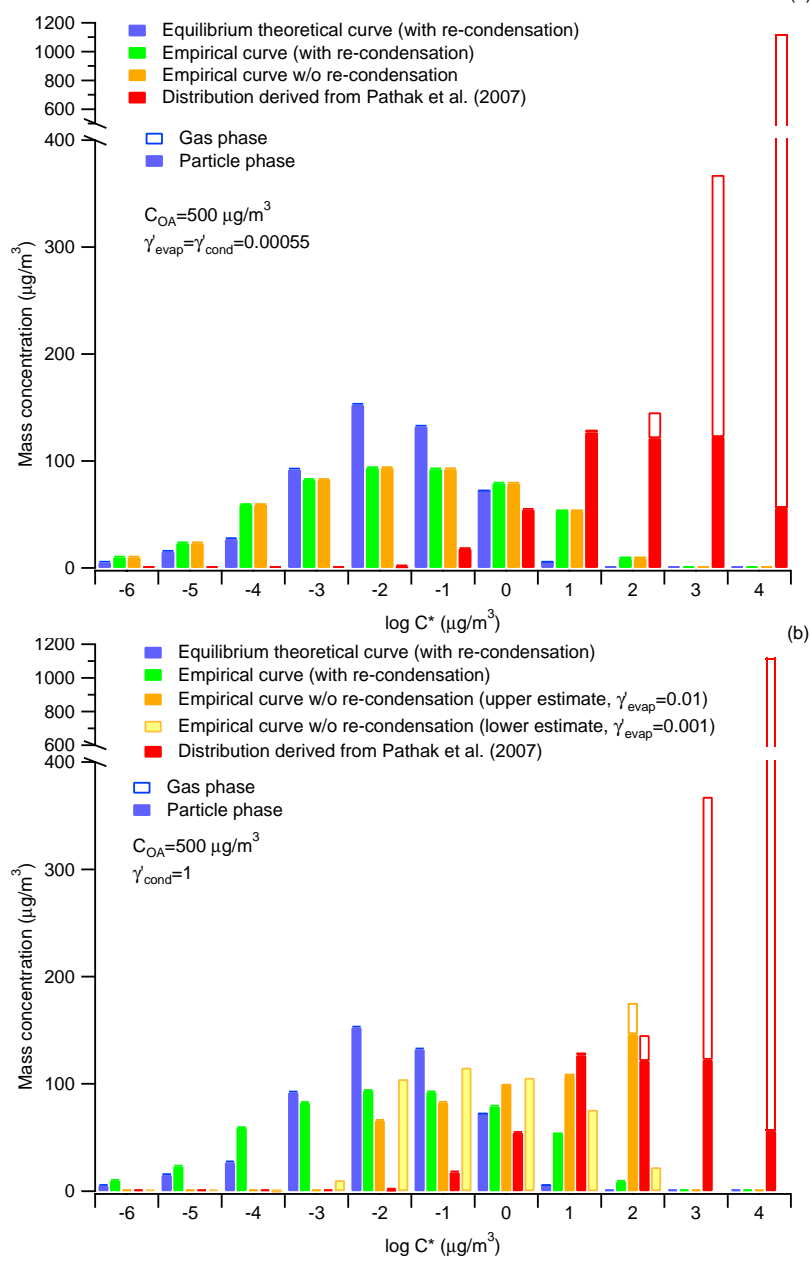

Fig. 15. Volatility distributions derived from $\alpha$-pinene SOA thermograms at $500 \mathrm{\mu g} \mathrm{m}^{-3}$ aerosol loading in comparison with the distribution derived using the parameterisation by Pathak et al. (2007). For case (a) the volatility is substantially underestimated due to the thermogram being significantly far from both the equilibrium and the empirical calibration curves region, while in (b) the deviation using the calibration curve approach is partly due to significant recondensation. Calculations for upper and lower estimates for recondensation are included for case (b).

limitation in using Faulhaber et al. (2009) method for deriving volatility from experiments with very high aerosol mass loadings. In this case re-condensation is also significant, as shown in the non-re-condensation distribution in Fig. 14b, which leads to an underestimation of the volatility distribution. The distribution obtained in this case for a lower estimate of re-condensation does not substantially differ from the upper estimate and has not been included in the figure for comparison.

For the $\alpha$-pinene SOA volatility study, the cases of (1) equal evaporation and re-condensation kinetic coefficients with a mean value of 0.00055 , and (2) independent coefficients for evaporation and re-condensation, with $\gamma_{\text {evap }}^{\prime}=0.0055$ and $\gamma_{\text {cond }}^{\prime}=1$ were considered. As explained in Sect. 5.2, the second case represents the evaporation of a glass-like SOA, whose re-condensation process is not limited by the particle phase and presents a re-condensation coefficient equal to unity. For the first case (Fig. 15a), the thermogram is very far from equilibrium (Fig. 9), because of the low kinetic coefficient, which leads to substantial underestimation of the volatility when using both the theoretical and empirical calibration curves. In this case, the prediction using both calibration equations is similar, due the curves becoming closer at high aerosol loadings, as previously shown. Because of the low accomodation coefficient, re-condensation is not significant in this case, which leads to equal volatility distributions for the cases with and without re-condensation.

For unequal evaporation and re-condensation kinetic coefficients (Fig. 15b), the distributions obtained indicate that the prediction using the calibration curves deviates substantially from the literature distribution due to the fact that equilibrium is not reached and also because the thermogram is strongly affected by re-condensation (Fig. 9). This occurs for both upper and lower estimates for re-condensation. The analysis presented here indicates that the interpretation of thermograms and prediction of volatility distributions from thermodenuder measurements is strongly affected by the assumption of equilibrium and the degree of disequilibrium resulting from kinetic limitation.

\subsection{Kinetic model approach}

The kinetic evaporation/re-condensation model was also applied to derive the aerosol volatility distribution from thermograms, following the approach of Cappa and Jimenez (2010). This method consists of the iterative estimation of the volatility basis set distributions by bringing into agreement the modeled and experimental thermograms (Cappa and Jimenez, 2010). The method to derive the volatility distribution is based on the assumption that the distribution follows an exponential function with an upper limit of $C^{*}=10^{4} \mu \mathrm{g} \mathrm{m}^{-3}$. The lower volatility bin limit was iterated to obtain agreement between measurements and model, which explains the large number of bins obtained in the volatility distributions.

Because this method requires specifying the effective kinetic coefficient, the volatility distributions inferred here were compared for a set of coefficient values, assuming equal kinetic coefficients for evaporation and re-condensation. In these calculations re-condensation is neglected. The thermodenuder measurements for $\alpha$-pinene SOA could not be adequately fitted with the model for kinetic coefficients above 0.01 , thus constraining these parameters to values $\leq 0.01$. In this model it was assumed that the enthalpy of vaporisation is a function of $C^{*}$, following Epstein equation. For different values of $\Delta H_{\mathrm{v}}$ to those derived from the Epstein equation, a different range of kinetic coefficient values would be possible. Figure 16 shows the volatility distributions 

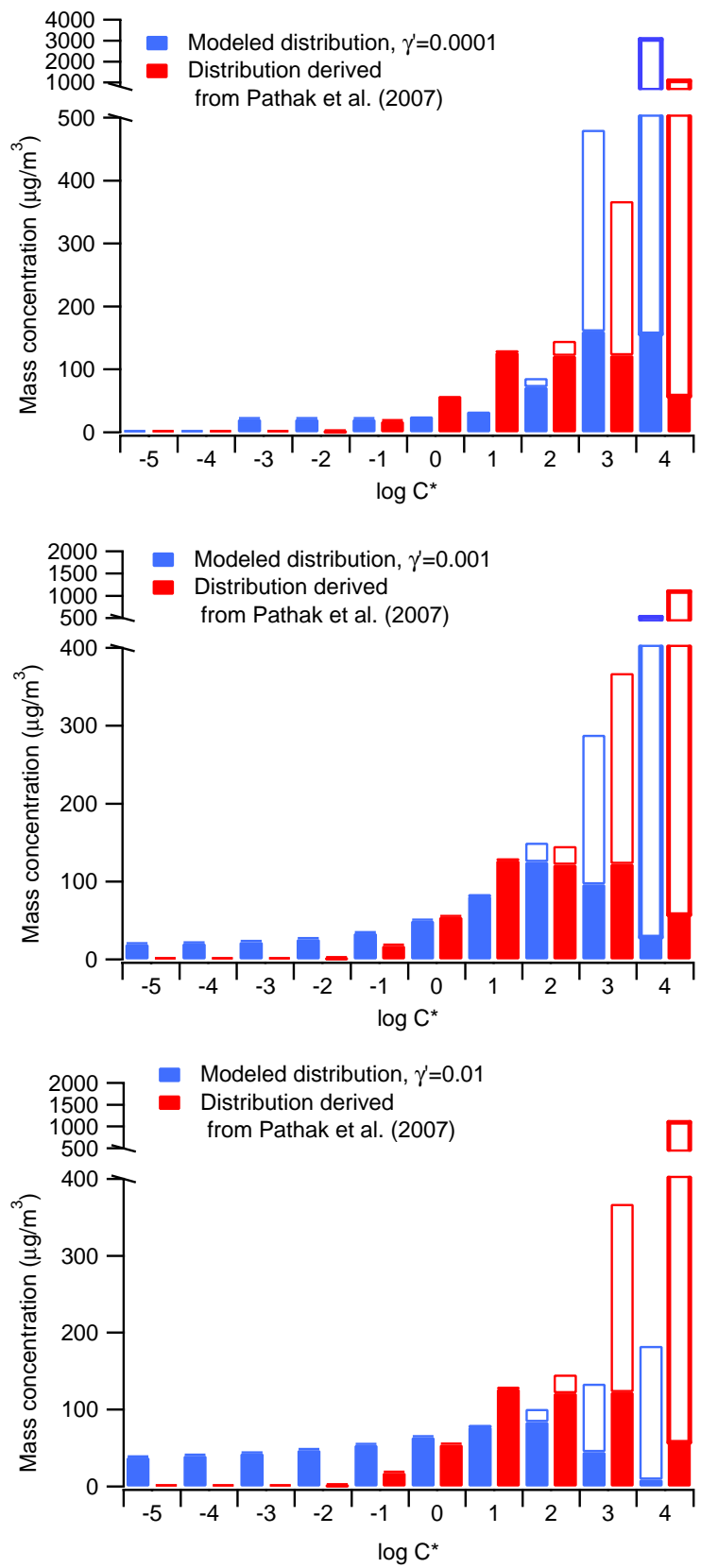

Fig. 16. Volatility distributions derived from $\alpha$-pinene SOA thermograms at $500 \mathrm{\mu g} \mathrm{m}^{-3}$ aerosol loading using the kinetic model approach with different kinetic coefficient values, in comparison with the distribution derived from data by Pathak et al. (2007). The derived distribution is sensitive to the assumption of effective kinetic coefficient, with a shift towards lower volatility for increasing kinetic coefficient.

derived from the $\alpha$-pinene SOA aerosol thermogram by applying the kinetic model (results of the fitting between model and measurements are presented in Fig. S8). The volatility distributions obtained with this method are highly sensitive to the assumption of kinetic coefficient. In this particular case, an overestimation and underestimation of the volatility is obtained for kinetic coefficients values of 0.0001 and 0.01 , respectively, while a reasonable agreement between the literature and estimated volatility distributions is obtained for an evaporation coefficient of 0.001 .

Volatility distributions for different groups of atmospheric organic aerosols, using a kinetic model, have been provided as an estimation for $\gamma^{\prime}=1$ (Cappa and Jimenez, 2010). It should be taken into account that it is unknown whether the different organic groups comprising atmospheric aerosols would present different effective kinetic coefficients. This implies a large uncertainty in interpreting the volatility distribution of organic aerosols and brings into question the volatility grading scale established for different organic compound groups by Cappa and Jimenez (2010). The fact that atmospheric measurements with thermodenuders will most likely not be at equilibrium poses a strong difficulty to accurately derive the volatility properties of aerosols from these type of measurements, as long as deviations from equilibrium are not more accurately constrained. Indeed, current uncertainty in determining volatility distributions for atmospheric samples will affect estimations of organic particle partitioning in atmospheric models, and modeling of organic aerosol CCN activity (Topping and McFiggans, 2012). Although models can be self-consistent if a given kinetic coefficient and its corresponding volatility distribution are used systematically, the quantitative results of models will primarily depend on the assumption of kinetic coefficient, thus, their outcome will be subject to the uncertainty associated to the value of this coefficient and its corresponding volatility distribution.

\section{Summary and conclusions}

In the present study a kinetic evaporation-condensation model was applied to analyse the uncertainty in estimating and interpreting the evaporation behaviour and volatility of aerosols from thermodenuder experiments.

Theoretical derivation of the empirical calibration curve between the saturation concentration $C^{*}$ and temperature at which $50 \%$ of the particle mass evaporates $\left(T_{50}\right)$ (Faulhaber et al., 2009), revealed that this relationship is based on the change in particle mass between equilibrium temperature states, expressed explicitly as a function of $C^{*}$ through the Clausius-Clapeyron equation. Calibration curve equations for a single component and multicomponent mixtures were theoretically derived and applied to estimate volatility distributions from equilibrium thermograms. Significant underestimation of the particle volatility resulted, however, when using the equilibrium calibration curve at kineticallycontrolled evaporation conditions. Because thermograms obtained at ambient aerosol loading levels would likely deviate from equilibrium, a kinetic approach constitutes a more adequate method to correctly interpret the particle evaporation behaviour of atmospheric samples. However, the application 
of the kinetic model approach to derive volatility distributions confers significant uncertainty, owing to sensitivity of the method to the assumption of evaporation coefficient.

Re-condensation was evaluated as a source of uncertainty for determining aerosol volatility distributions from thermodenuder measurements, because of its potential to affect thermograms. A parametric analysis showed that the recondensation yield is highly determined by the combined effects of aerosol loading, particle size and effective kinetic coefficient for re-condensation. This dependence results in either important or negligible re-condensation at higher aerosol mass loadings, depending on the thermodenuder configuration and the properties of the aerosol sample. Analysis of the effect of denuders on particle evaporation indicated that experimental thermograms may be modified in the region below $45^{\circ} \mathrm{C}$ as a result of evaporation induced by the charcoal denuder at atmospheric aerosol levels.

Estimation of effective kinetic evaporation coefficient values from experimental evaporation measurements with lubricating oil aerosol revealed the existence of artefacts in the evaporation occurring in standard chamber dilution experiments, which is manifested as a notable deceleration of the particle evaporation rate, presumably resulting from the release of material from the chamber walls. From this analysis it is concluded that dilution experiments with standard Teflon walls do not seem to be an adequate methodology for conducting this type of studies.

Analysis in this study points at the effective kinetic coefficient defined in an evaporation/re-condensation model as a critical unknown to both determining the volatility properties of atmospheric samples and determining the atmospheric dynamics of SOA. Simulation of the evaporation-condensation behaviour of amorphous solid $\alpha$-pinene SOA, pointed at a large uncertainty in estimating the aerosol mass formation induced by cooling, depending on whether or not it is assumed that gas condensation is affected by the amorphous solid state of the particles. Analysis of dilution-induced evaporation of $\alpha$-pinene SOA indicated an underprediction of the aerosol mass in a factor from 5 to 10 , when using equilibrium partitioning theory with respect to the kinetic calculations for an effective evaporation coefficient between 0.01-0.0001. Predictions with the kinetic model were found to be highly sensitive to the assumption of effective evaporation coefficient. Better constraints on this parameter are therefore required to model the particle mass variation upon atmospheric dilution and cooling for glass-like SOA. Current modules to predict SOA formation in the atmosphere are based on empiricallyderived mass fraction parameterisations (e.g. Strader et al., 1999) and do not account for kinetic limitations to evaporation/condensation of amorphous SOA. This study demonstrates that it is necessary to use kinetic approaches (including estimations of kinetic coefficients), alongside volatility information, to implement reasonable gas-aerosol partitioning modules in transport models that include glass-like SOA.
Supplementary material related to this article is available online at: http://www.atmos-meas-tech.net/5/ 735/2012/amt-5-735-2012-supplement.pdf.

Acknowledgements. This work was supported by the UK Natural Environment Research Council [grant number NE/H002561/1].

Edited by: H. Herrmann

\section{References}

An, W. J., Pathak, R. K., Lee, B. H., and Pandis, S. N.: Aerosol Volatility Measurement Using an Improved Thermodenuder: Application to Secondary Organic Aerosol, J. Aerosol Sci, 38, 305-314, 2007.

Bilde, M., Svenningsson, B., Monster, J. and Rosenorn, T.: EvenOdd Alternation of Evaporation Rates and Vapor Pressures of C3-C9 Dicarboxylic Acid Aerosols, Environ. Sci. Technol, 37, 1371-1378, 2003.

Burtscher, H., Baltensperger, U., Bukowiecki, N., Cohn, P., Huglin, C., Mohr, M., Matter, U., Nyeki, S., Schmatloch, V., Streit, N., and Weingartner, E.: Separation of Volatile and Non-Volatile Aerosol Fractions by Thermodesorption: Instrumental Development and Applications, J. Aerosol Sci. 32, 427-442, 2001.

Campo, A.: On the Asymptotic Solution of the Graetz-Nusselt Problem for Short $\mathrm{x} \rightarrow 0$ and Large $\mathrm{x} \rightarrow \infty$ with Partial Usage of Finite Differences, Numer. Meth. Part. D. E., 20, 6, 820-830, 2004.

Cappa, C. D.: A model of aerosol evaporation kinetics in a thermodenuder, Atmos. Meas. Tech., 3, 579-592, doi:10.5194/amt3-579-2010, 2010.

Cappa, C. D. and Jimenez, J. L.: Quantitative estimates of the volatility of ambient organic aerosol, Atmos. Chem. Phys. Discuss., 10, 1901-1938, doi:10.5194/acpd-10-1901-2010, 2010.

Cappa, C. D. and Wilson, K. R.: Evolution of organic aerosol mass spectra upon heating: implications for OA phase and partitioning behavior, Atmos. Chem. Phys., 11, 1895-1911, doi:10.5194/acp11-1895-2011, 2011.

Chattopadhyay, S. and Ziemann, P. J.: Vapor pressures of substituted and unsubstituted monocarboxylic and dicarboxylic acids measured using an improved thermal desorption particle 25 beam mass spectrometry method, Aerosol Sci. Tech., 39, 1085-1100, 2005.

Chickos, J. S. and Hanshaw, W.: Vapor Pressures and Vaporization Enthalpies at $298.15 \mathrm{~K}$ of the n-Alkanes from C21 to C28 and C30, J. Chem. Eng. Data, 42, 190-197, 1997.

Davies, M. and Thomas, G. H.: The Lattice Energies, Infra-Red Spectra, and Possible Cyclization of Some Dicarboxylic Acids, Trans. Faraday Soc., 56, 185-192, 1960.

Donahue, N. M., Epstein, S. A., Pandis, S. N., and Robinson, A. L.: A two-dimensional volatility basis set: 1. organic-aerosol mixing thermodynamics, Atmos. Chem. Phys., 11, 3303-3318, doi:10.5194/acp-11-3303-2011, 2011.

Epstein, S. A., Riipinen, I., and Donahue, N. M.: A Semiempirical Correlation between Enthalpy of Vaporization and Saturation Concentration for Organic Aerosol, Environ. Sci. Technol., 44, 743-748, doi:10.1021/es902497z, 2009. 
Faulhaber, A. E., Thomas, B. M., Jimenez, J. L., Jayne, J. T., Worsnop, D. R., and Ziemann, P. J.: Characterization of a thermodenuder-particle beam mass spectrometer system for the study of organic aerosol volatility and composition, Atmos. Meas. Tech., 2, 15-31, doi:10.5194/amt-2-15-2009, 2009.

Fuchs, N. A. and Sutugin, A. G.: Highly dispersed aerosols. Ann Arbor Science Publishers, Ann Arbor, London, 1970.

Grieshop, A. P., Miracolo, M. A., Donahue, N. M., and Robinson, A. L.: Constraining the Volatility Distribution and Gas-Particle Partitioning of Combustion Aerosols Using Isother- 20 mal Dilution and Thermodenuder Measurements, Environ. Sci. Technol., 43, 4750-4756, doi:10.1021/es8032378, 2009.

Hallquist, M., Wenger, J. C., Baltensperger, U., Rudich, Y., Simpson, D., Claeys, M., Dommen, J., Donahue, N. M., George, C., Goldstein, A. H., Hamilton, J. F., Herrmann, H., Hoffmann, T., Iinuma, Y., Jang, M., Jenkin, M. E., Jimenez, J. L., Kiendler-Scharr, A., Maenhaut, W., McFiggans, G., Mentel, Th. F., Monod, A., Prévôt, A. S. H., Seinfeld, J. H., Surratt, J. D., Szmigielski, R., and Wildt, J.: The formation, properties and impact of secondary organic aerosol: current and emerging issues, Atmos. Chem. Phys., 9, 5155-5236, doi:10.5194/acp-95155-2009, 2009.

Huffman, J. A., Ziemann, P. J., Jayne, J. T., Worsnop, D. R., and Jimenez, J. L.: Development and characterization of a fast-stepping/scanning thermodenuder for chemically-resolved 5 aerosol volatility measurements, Aerosol Sci. Technol., 42, 395407, 2008

Jimenez, J. L., Canagaratna, M. R., Donahue, N. M., Prevot, A. S. H., Zhang, Q., Kroll, J. H., DeCarlo, P. F., Allan, J. D., Coe, H., Ng, N. L., Aiken, A. C., Docherty, K. S., Ulbrich, I. M., Grieshop, A. P., Robinson, A. L., Duplissy, J., Smith, J. D., Wilson, K. R., Lanz, V. A., Hueglin, C., Sun, Y. L., Tian, J., Laaksonen, A., Raatikainen, T., Rautiainen, J., Vaattovaara, P., Ehn, M., Kulmala, M., Tomlinson, J. M., Collins, D. R., Cubison, M. J., , Dunlea, J., Huffman, J. A., Onasch, T. B., Alfarra, M. R., Williams, P. I., Bower, K., Kondo, Y., Schneider, J., Drewnick, F., Borrmann, S., Weimer, S., Demerjian, K., Salcedo, D., Cottrell, L., Griffin, R., Takami, A., Miyoshi, T., Hatakeyama, S., Shimono, A., Sun, J. Y., Zhang, Y. M., Dzepina, K., Kimmel, J. R., Sueper, D., Jayne, J. T., Herndon, S. C., Trimborn, A. M., Williams, L. R., Wood, E. C., Middlebrook, A. M., Kolb, C. E., Baltensperger, U., and Worsnop, D. R.: Evolution of Organic Aerosols in the Atmosphere, Science, 326, 1525-1529, 2009.

Kanakidou, M., Seinfeld, J. H., Pandis, S. N., Barnes, I., Dentener, F. J., Facchini, M. C., Van Dingenen, R., Ervens, B., Nenes, A., Nielsen, C. J., Swietlicki, E., Putaud, J. P., Balkanski, Y., Fuzzi, S., Horth, J., Moortgat, G. K., Winterhalter, R., Myhre, C. E. L., Tsigaridis, K., Vignati, E., Stephanou, E. G., and Wilson, J.: Organic aerosol and global climate modelling: a review, Atmos. Chem. Phys., 5, 1053-1123, doi:10.5194/acp-5-1053-2005, 2005.

Kulikov, D., Verevkin, S. P., and Heintz, A.: Enthalpies of vaporization of a series of aliphatic alcohols: Experimental results and values predicted by the ERAS-model. Fluid Phase Equilibria, 192, 187-207, 2001.

Laaksonen, A., Vesala, T., Kulmala, M., Winkler, P. M., and Wagner, P. E.: Commentary on cloud modelling and the mass accommodation coefficient of water, Atmos. Chem. Phys., 5, 461-464, doi:10.5194/acp-5-461-2005, 2005.
Lehtinen, K., Korhonen, H., Dal Maso, M., and Kulmala, M.: On the concept of condensation sink diameter, Boreal Environ. Res., 8, 405-411, 2003.

Matsunaga, A. and Ziemann, P. J.: Gas-wall partitioning of organic compounds in a Teflon film chamber and potential effects on reaction product and aerosol yield measurements, Aerosol Sci. Tech., 44, 881-892, 2010.

Offenberg, J. H., Kleindienst, T. E., Jaoui, M., Lewandowski, M., and Edney, E. O.: Thermal properties of secondary organic aerosols, Geophys. Res. Lett., 33, L03816, doi:10.1029/2005GL024623, 2006.

Orsini, D. A., Wiedensohler, A., and Stratmann, F.: Covert, D. S. J., Atmos. Ocean. Technol., 16, 760-772, 1999.

Pankow, J. F.: An absorption model of the gas/aerosol partitioning involved in the formation of secondary organic aerosol, Atmos. Environ., 28, 189-193, 1994.

Pathak, R. K., Presto, A. A., Lane, T. E., Stanier, C. O., Donahue, N. M., and Pandis, S. N.: Ozonolysis of $\alpha$-pinene: parameterization of secondary organic aerosol mass fraction, Atmos. Chem. Phys., 7, 3811-3821, doi:10.5194/acp-7-3811-2007, 2007.

Pfrang, C., Shiraiwa, M., and Pöschl, U.: Chemical ageing and transformation of diffusivity in semi-solid multi-component organic aerosol particles, Atmos. Chem. Phys., 11, 7343-7354, doi:10.5194/acp-11-7343-2011, 2011.

Riipinen, I., Pierce, J. R., Donahue, N. M., and Pandis, S. N.: Equilibration time scales of organic aerosol inside thermodenuders: Evaporation kinetics versus thermodynamics, Atmos. Environ., 44, 597-607, 2010.

Sakurai, H., Park, K., McMurry, P., Zarling, D., Kittelson, D., and Ziemann, P.: Size-dependent mixing characteristics of volatile and nonvolatile components in diesel exhaust aerosols, Environ. Sci. Technol., 37, 5487-5495, 2003.

Saleh, R., Walker, J., and Khlystov, A.: Determination of saturation pressure and enthalpy of vaporisation of semi-volatile aerosols: the integrated volume method, J. Aeros. Sci., 39, 876-887, 2008.

Saleh, R., Shihadeh, A., and Khlystov, A.: On transport phenomena and equilibration time scales in thermodenuders, Atmos. Meas. Tech., 4, 571-581, doi:10.5194/amt-4-571-2011, 2011.

Saleh, R., Khlystov, A., and Shihadeh, A.: Determination of evaporation coefficients of ambient and laboratory-generated semivolatile organic aerosols from phase equilibration kinetics in a thermodenuder, Aerosol Sci. Technol., 46, 22-30, 2012.

Shimada, M., Seto, T., and Okuyama, K.: Thermophoretic and evaporational losses of ultrafine particles in heated flow, AIChE J., 39, 1859-1869, 1993.

Seinfeld, J. H. and Pandis, S. N.: Atmospheric Chemistry and Physics: From Air Pollution to Climate Change, WileyInterscience, ISBN 0471178160, 1997.

Skeel, R. D. and Berzins, M.: A Method for the Spatial Discretization of Parabolic Equations in One Space Variable, SIAM J. Sci. Stat. Comp., 11, 1-32, 1990.

Strader, R., Lurmann, F., and Pandis, S. N.: Evaluation of secondary organic aerosol formation in winter, Atmos. Environ., 33, 48494863, 1999.

Tan, C. W. and Hsu, C.: Mass transfer of decaying products with axial diffusion in cylindrical tubes, Int. J. Heat mass Transfer., 13, 1887-1905, 1970.

Tong, H.-J., Reid, J. P., Bones, D. L., Luo, B. P., and Krieger, U. K.: Measurements of the timescales for the mass transfer of water in 
glassy aerosol at low relative humidity and ambient temperature, Atmos. Chem. Phys., 11, 4739-4754, doi:10.5194/acp-11-47392011, 2011.

Topping, D. O. and McFiggans, G.: Tight coupling of particle size, number and composition in atmospheric cloud droplet activation, Atmos. Chem. Phys., 12, 3253-3260, doi:10.5194/acp-12-32532012, 2012.

Topping, D. O., Barley, M. H., and McFiggans, G.: The sensitivity of Secondary Organic Aerosol component partitioning to the predictions of component properties: part 2; determination of particle hygroscopicity and its dependence on "apparent" volatility, Atmos. Chem. Phys., 11, 7767-7779, doi:10.5194/acp-11-77672011, 2011.

Tsigaridis, K. and Kanakidou, M.: Secondary organic aerosol importance in the future atmosphere, Atmos. Environ., 41, 46824692, 2007.
Turpin, B. J., Liu, S. P., Podolske, K. S., Gomes, M. S. P., Eisenreich, S. J., and McMurry, P. H.: Design and evaluation of a novel diffusion separator for measuring gas/particle distributions of semivolatile organic compounds, Environ. Sci. Technol. 1993 27, 2441-2449.

Vaden, T. D., Song, C., Zaveri, R. A., Imre, D., and Zelenyuk, A.: Morphology of mixed primary and secondary organic particles and the adsorption of spectator organic gases during aerosol formation, P. Natl. Acad. Sci. USA, 107, 6658-6663, 2010.

Wehner, B., Philippin, S., and Wiedensohler, A.: Design and Calibration of a Thermodenuder with an Improved Heating Unit to Measure the Size- Dependent Volatile Fraction of Aerosol Particles, J. Aerosol Sci., 33, 1087-1093, 2002. 